\title{
Isolation and characterization of broad host-range of bacteriophages infecting Cronobacter sakazakii and its biocontrol potential in dairy products
}

\author{
Hua-xiang Li ${ }^{1 *}$, Xiao-jun Yang ${ }^{1 *}$, Xiao-yan $\mathrm{Zhu}^{2}$, Lu Gao ${ }^{1 *}$, Sheng-qi Rao ${ }^{3}$, Lei Yuan ${ }^{1}$, Zhen-quan Yang ${ }^{1,2 *}$ \\ ${ }^{1}$ College of Food Science and Engineering, Yangzhou University, Yangzhou, Jiangsu, China; ${ }^{2}$ Jiangsu Provincial Key \\ Construction Laboratory of Probiotics Preparation, Huaiyin Institute of Technology, Huaian, China; ${ }^{3}$ Jiangsu Key \\ Laboratory of Dairy Biotechnology and Safety Control, Yangzhou University, Yangzhou, Jiangsu, China
}

"These authors contributed equally to this study and shared first authorship.

*Corresponding authors: Lu Gao and Zhen-quan Yang, College of Food Science and Engineering, Yangzhou University, No. 196 West Huayang Road, Yangzhou, Jiangsu 225009, China. Emails: gaolu@yzu.edu.cn and yangzq@yzu.edu.cn

Received: 31 December 2020; Accepted: 22 June 2021; Published: 6 August 2021

(c) 2021 Codon Publications

OPEN ACCESS (C) (1) (2) (2)

RESEARCH ARTICLE

\begin{abstract}
Cronobacter sakazakii (C. sakazakii) is an important pathogen contaminating dairy products (e.g., milk powder) and causes high mortality in infants. Bacteriophage as a potential biocontrol agent is a good alternative method for the control of this pathogen in dairy production and its environment. Thus, it is important to complete the C. sakazakii phage library by isolating and characterizing the broad host range of bacteriophage against C. sakazakii for control use. In this study, C. sakazakii strains from different sources were used as hosts to isolate and purify phages from human stool and sewage samples by double-layer plates. The biological characteristics, antibacterial properties, and genomes of these phages were then studied. Finally, ten virulent phages (EspYZU01-EspYZU10) infecting C. sakazakii were isolated and identified as belonging to the Myoviridae, Podoviridae, Tectivirus, and Stylovinidae families. Phage EspYZU08 presented the broadest host range and could infect all the five host strains of C. sakazakii. All 10 phages retained their infectivity at $50^{\circ} \mathrm{C}$ and pH 5-9. Both genomes of EspYZU05 and EspYZU08 were double-stranded DNAs with sizes of 41723 bp and $145582 \mathrm{bp}, \mathrm{G}+\mathrm{C}$ contents of $55.69 \%$ and $46.75 \%$, and open reading frames of 47 and 103, respectively. No toxins and antibiotic resistance genes were detected in both EspYZU05 and EspYZU08. Phage EspYZU08 and phage cocktail-3 (EspYZU01 + EspYZU03 + EspYZU08 + EspYZU09 + EspYZU10) presented excellent antibacterial efficacy for C. sakazakii in liquid broth and milk at $4{ }^{\circ} \mathrm{C}, 25^{\circ} \mathrm{C}$, and $37^{\circ} \mathrm{C}$, suggesting that the phages in this study have great potential for the development of biocontrol agents against C. sakazakii in dairy and its processing environment.
\end{abstract}

Keywords: Cronobacter sakazakii; bacteriophage; antibacterial effects; genome; biocontrol

\section{Introduction}

Before 1980, Cronobacter sakazakii (C. sakazakii) was known as Enterobacter cloacae. Then, till 2007, Enterobacter cloacae was named as Enterobacter sakazakii. It was then reclassified into genus Cronobacter on the basis of its nucleotide sequence (Farmer et al., 1980; Iversen et al., 2007). The Cronobacter genus includes the following seven species: C. sakazakii, C. malonaticus, C. turicensis, C. universalis, C. muytjensii, C. dublinensis, and C. condimenti (Brady et al., 2013; Joseph et al., 2012). C. sakazakii is ubiquitous in nature and thus can 
be isolated from the environment and food materials and products, including dried foods and water (Healy et al., 2010; Kandhai et al., 2004). C. sakazakii has higher tolerance to desiccation, osmotic stress, and heat stress than other members of Enterobacteriaceae (Asakura et al., 2007), contributing to its survival in desiccation and osmotic stress environments, typical of powdered infant formula.

In recent years, C. sakazakii, as an emerging food-borne pathogen, has gained more and more attention. Genus Cronobacter can cause severe diseases, including bacteremia, sepsis, brain abscess, meningitis, and necrotizing enterocolitis in immunocompromised neonates, especially in pre-term and low birth weight infants (Drudy et al., 2006; Lai, 2001; Nazarowec-White and Farber, 1997; Yan et al., 2012). Besides, genus Cronobacter causes urosepsis, pneumonia, and bacteremia in immunocompromised adults, especially in the elderly population (Hawkins et al., 1991; Lai, 2001; See et al., 2007). In the United States, incidences of 1 Cronobacter infection per 100,000 infants, 8.7 Cronobacter infections per 100,000 low birth weight neonates (Himelright et al., 2001), and 1 Cronobacter infection per 10,660 very-low birth weight neonates (Stoll et al., 2004) have been reported. Although the incidence rate of C. sakazakii infection is low, fatality because of its infection is as high as $80 \%$ (Friedemann, 2009). One of the most severe outbreaks of C. sakazakii infection was in a neonatal intensive care unit of France in 1994, which lasted for more than 3 months, infecting 17 neonates and claiming three lives (Caubilla-Barron et al., 2007). Further, 18 cases of (meningitis or) bacteraemia in infants aged 1-11 months have been reported in the United Kingdom by the Food and Agriculture Organization/World Health Organization (FAO/WHO) during 1997-2007, and in 2008, 27 clinical Cronobacter isolates from young children aged 1-4 years have been reported in England and Wales (FAO/ WHO, 2008). Besides, the C. sakazakii outbreaks were also reported in Belgium during 1997-1998, in Austria during 2009 -2016, and in France during 2010-2016 (Lepuschitz et al., 2009). Prevalence of infection, high mortality rates, and associated chronic neurological and developmental disorders in many survivors highlight the damaging effects of this organism on infant health (Forsythe, 2005; Lai, 2001). Thus, the International Commission for Microbiological Specifications for Foods (ICMSF), which was formed in 1962 through the action of the International Committee on Food Microbiology and Hygiene as a committee of the International Union of Microbiological Societies (IUMS) and linked to the International Union of Biological Societies (IUBS) and the World Health Organization (WHO) of the United Nations, has ranked C. sakazakii as a 'severe hazard for restricted populations, life threatening or substantial chronic sequelae of long duration', and has classified it with Clostridium botulinum, Cryptosporidium parvum, and Listeria monocytogenes (Abbasifar et al., 2014).

Therefore, it is important to minimize the risk of C. sakazakii contamination in foods by developing novel alternative biocontrol agents. Bacteriophages are recognized as safe, host-specific, and effective alternatives for the prevention and/or eradication of food-borne pathogens in foods and their processing environments. In fact, bacteriophages have been applied in the decontamination of livestock; sanitation of contact surfaces and equipment; and biocontrol of raw meats, fresh foods, and vegetables (Endersen et al., 2014; Goodridge and Bisha, 2014), cheese (Carlton et al., 2005), ready-to-eat foods (Bigot et al., 2011), skim milk (Ellis et al., 1973; Endersen et al., 2013), and reconstituted infant formula (Kim et al., 2007). Selected C. sakazakii phages were used to inhibit growth of C. sakazakii in the formula and show high efficiency (Kim et al., 2007). Furthermore, 67 newly isolated C. sakazakii phages have been tested, some of which have reduced C. sakazakii up to $4 \log (\mathrm{CFU} / \mathrm{mL})$ in pure broth culture, which shows that the C. sakazakii phages have a great potential of being a biocontrol agent for controlling C. sakazakii in foods (Zuber et al., 2008). In addition, C. sakazakii phages also exhibit excellent efficiency in alleviating Cronobacter-induced urinary tract infections in mice (Tóthová et al., 2011).

These studies demonstrate that bacteriophages are promising natural agents for the control of C. sakazakii. Although a total of 21 genomes of phages infecting $C$. sakazakii have been published in the National Center for Biotechnology Information (NCBI) database (https:// www.ncbi.nlm.nih.gov/genome) so far, the library of C. sakazakii phages and their genomic information are still limited for developing biocontrol agents, because $C$. sakazakii strains are of high diversity and tend to become phage-resistant. Therefore, new broad host range phages must be isolated, and phage cocktails must be created as broad-spectrum food biocontrol agents against $C$. sakazakii.

In this study, human stool samples and sewage samples were used to isolate broad-spectrum virulent phages against C. sakazakii. In all, 10 bacteriophages infecting C. sakazakii were isolated and purified, and their morphological features, dynamics of infection, and host range were characterized. In addition, genomes of two broad-spectrum phages (EspYZU05 and EspYZU08) were completely sequenced to understand their characteristics. On the basis of these results, cocktail of virulent phages were prepared and evaluated for their potential and efficacy in the biocontrol of C. sakazakii strains in the liquid broth and milk medium under different temperatures and $\mathrm{pH}$ values to evaluate their possibility of being novel and efficient biocontrol agents. 


\section{Materials and Methods}

All the chemicals used in this study, except for nutrient broth, were of analytical grade and purchased from Sangon Biotech Co. Ltd. (Shanghai).

\section{Bacterial strains and cultivation}

C. sakazakii strains CICC 21560, CICC 21545, CICC 21569, CICC 21673, and CICC 22919 were used as bacterial hosts for isolating phages in this study. These strains were purchased from the China Industrial Culture Collection Center. The strains were stored at $-80^{\circ} \mathrm{C}$ and routinely based on nutrient agar and nutrient broth (Hangzhou Microbial Reagent Co. Ltd.) at $37^{\circ} \mathrm{C}$.

\section{Collection of samples}

A total of 100 samples of human stool were collected from patients suspected of C. sakazakii infection in the Affiliated Hospital of Yangzhou University, Yangzhou, Jiangsu, China after signing the consent. Apart from these, 12 raw sewage samples were collected from Kangyuan Dairy Co. Ltd. (Yangzhou, Jiangsu, China).

\section{Isolation and purification of phages}

In order to isolate bacteriophages, we homogenized $25 \mathrm{~mL}$ of fresh sewage or $5 \mathrm{~g}$ of stool sample with $45 \mathrm{~mL}$ of sodium chloride-magnesium sulfate (SM) buffer $(\mathrm{NaCl}$, $5.8 \mathrm{~g} ; \mathrm{MgSO}_{4} \cdot 7 \mathrm{H}_{2} \mathrm{O}, 2 \mathrm{~g}$; Tris- $\mathrm{HCl} 1 \mathrm{~mol} / \mathrm{L}$ [pH 7.5], $50 \mathrm{~mL}$; gelatin, $0.1 \mathrm{~g}$ : dissolved in distilled water to a final volume of $1 \mathrm{~L}$ ). After overnight incubation at $4^{\circ} \mathrm{C}$, the homogenized sample was centrifuged at $5,000 \times \mathrm{g}$ for $10 \mathrm{~min}$ at $4^{\circ} \mathrm{C}$, and the supernatant was filtered using sterile $0.22-\mu \mathrm{m}$ membrane. Afterward, $5 \mathrm{~mL}$ of filtrate and $100 \mu \mathrm{L}$ of host bacteria (C. sakazakii) suspension in logarithmic growth phase were aseptically added to a tube with 5 -mL nutrient broth incubated overnight at $37^{\circ} \mathrm{C}$ with continuous shaking at a speed of $120 \mathrm{rpm} / \mathrm{min}$. After incubation, the broth was centrifuged at $5,000 \times \mathrm{g}$ for $10 \mathrm{~min}$ at $4^{\circ} \mathrm{C}$. The phage suspended in the semen was filtered through a sterile $0.22-\mu \mathrm{m}$ membrane to remove residual bacterial cells.

Thereafter, the presence of viable infective phages in supernatant was tested by a two-layer plating method. The supernatant $(100 \mu \mathrm{L})$ was mixed with host bacteria $(100 \mu \mathrm{L})$ in early logarithmic growth phase and added to a tube with $5 \mathrm{~mL}$ of soft nutrient agar ( $0.7 \%$ agar), tempered to $37^{\circ} \mathrm{C}$, and thereafter poured onto the surface of a nutrient agar plate (2\% agar). The plates were incubated overnight at $37^{\circ} \mathrm{C}$ and examined for phage plaques. Extract a single phage plaque and resuspend it in SM buffer. The isolation processes were repeated for three to five times to purify individual phages.

\section{Amplification and collection of phages}

Inoculation of $5 \mathrm{~mL}$ of the mixture of host bacteria and bacteriophages into $500 \mathrm{~mL}$ of fresh nutrient broth was performed and shaken overnight at $37^{\circ} \mathrm{C}$ at a speed of $120 \mathrm{rpm} / \mathrm{min}$. After phage propagation and amplification, the lysates were treated with DNase I and RNase A with a final concentration of $1 \mu \mathrm{g} / \mathrm{mL}$ at $37^{\circ} \mathrm{C}$ for $30 \mathrm{~min}$ and then with $1 \mathrm{~mol} / \mathrm{L} \mathrm{NaCl}$ in ice for $1 \mathrm{~h}$. The host cell fragments were removed at a $10,000 \times$ g centrifugation of $10 \mathrm{~min}$ at $4^{\circ} \mathrm{C}$. Phage particles were concentrated in $10 \%$ $(\mathrm{w} / \mathrm{v})$ polyethylene glycol 8,000 by overnight incubation in ice. The phages were pelleted by $11,000 \times \mathrm{g}$ centrifugation for $15 \mathrm{~min}$ at $4^{\circ} \mathrm{C}$ and resuspended in $1 \mathrm{~mL}$ of $\mathrm{SM}$ buffer. The phages were treated with $1 \mathrm{~mL}$ of chloroform and centrifuged at $3,000 \times \mathrm{g}$ for $15 \mathrm{~min}$ at $4{ }^{\circ} \mathrm{C}$. Phages dispersed in the upper aqueous phase were collected. The aqueous phase was overlaid on a $\mathrm{CsCl}$ step gradient (density $=1.4,1.5$, and $1.7 \mathrm{~g} / \mathrm{mL}, 1 \mathrm{~mL}$ each step) in $5-\mathrm{mL}$ centrifuge tube and horizontal centrifuge at 22,000 $\times$ $\mathrm{g}$ for $2 \mathrm{~h}$ at $4^{\circ} \mathrm{C}$. The phage band (density between 1.5 and $1.7 \mathrm{~g} / \mathrm{mL}$ ) was drawn through the wall of centrifuge tube by using a syringe and stored at $4{ }^{\circ} \mathrm{C}$ for further experiments.

\section{Determination of phage titer}

First, the purified phages were diluted for 10 times with SM buffer. Thereafter, $100 \mu \mathrm{L}$ of phage suspension was mixed with $100 \mu \mathrm{L}$ of host bacterium suspension. The mixture was added to $5 \mathrm{~mL}$ of nutrient broth incubated at $37^{\circ} \mathrm{C}$ for $12 \mathrm{~h}$ with continuous shaking at $120 \mathrm{rpm} /$ min. The culture medium was centrifuged at 5,000 $\times \mathrm{g}$ for $10 \mathrm{~min}$ at $4^{\circ} \mathrm{C}$, and the supernatant was filtered through a sterile $0.22-\mu \mathrm{m}$ membrane filter. Subsequently, $100 \mu \mathrm{L}$ of filtrate (phage suspension) was serially diluted with a gradient to 10 -fold, mixed with $100 \mu \mathrm{L}$ of host bacterium suspension $\left(\sim 10^{9} \mathrm{CFU} / \mathrm{mL}\right)$, and incubated for $10 \mathrm{~min}$ at $37^{\circ} \mathrm{C}$. Then the mixture was added to $5 \mathrm{~mL}$ of soft agar and spread on nutrient broth agar plates. The titers of the phages were determined by the soft agar overlay method. All assays were carried out in triplicate.

\section{Transmission electron microscope}

Phage morphology was observed by TEM (Phenom XL $\mathrm{G} 2$, the Netherlands) analysis. $\mathrm{CsCl}$ phage suspension was dropped on the membrane side of 400 mesh copper grid. After 10 min of adsorption, excess solution was removed with a bibulous paper. The copper grid was treated for 2 
min in a drop of $2 \%$ phosphotungstic acid, and excess liquid was removed by infrared light. Finally, the specimens were examined and the morphology and dimensions of phages were recorded with a Tecnai-12 TEM.

\section{Host range activity}

Soft agar, $5 \mathrm{~mL}$, containing $100 \mu \mathrm{L}$ of host bacteria was overlaid on $1.5 \%$ nutrient agar plates. Then $10 \mu \mathrm{L}$ of phage suspension $\left(\sim 10^{9} \mathrm{PFU} / \mathrm{mL}\right)$ was spotted on the overlaid plates and dried with blotting paper. Petri dish was cultured for $8-12 \mathrm{~h}$ at $37^{\circ} \mathrm{C}$. The lysis activity of the test bacteria by phages was determined by counting the plaques of spots.

\section{Effect of heat treatment on phage infectivity}

In order to determine the effect of temperature on phages, we placed $500 \mu \mathrm{L}$ of phage suspension in water bath at 50,60 , and $70^{\circ} \mathrm{C}$. Subsequently, $100 \mu \mathrm{L}$ of phage suspension was immediately obtained for phage titer measurement for 20, 40, and $60 \mathrm{~min}$ as described in Section 2.5. Measurement was replicated for three times, and the average values were used for analysis.

\section{Effect of pH on phage infectivity}

Effect of $\mathrm{pH}$ on phage activity was determined in nutrient solution with different $\mathrm{pH}$ values ( $\mathrm{pH} 3-11)$. In general, 50 $\mu \mathrm{L}$ of phage suspension was mixed with $950 \mu \mathrm{L}$ of nutrient broth adjusted to $\mathrm{pH}$ of $3-11$ and incubated at $37^{\circ} \mathrm{C}$ for $2 \mathrm{~h}$. Subsequently, as described in Section 2.5, $100 \mu \mathrm{L}$ of phage suspension was obtained immediately for phage titer measurement. All assays were performed in triplicate.

\section{Optimization of MOI}

MOI is a ratio of virus particles to potential host cells. The host cells were infected with phages in different ratios $(0.001,0.01,0.1,1$, and $10 \mathrm{PFU} / \mathrm{CFU})$ and incubated at $37^{\circ} \mathrm{C}$ for $6 \mathrm{~h}$. The culture medium was centrifuged at $5,000 \times \mathrm{g}$ at $4^{\circ} \mathrm{C}$ for $10 \mathrm{~min}$. The supernatant was filtered through sterile $0.22-\mu \mathrm{m}$ membrane filter, and phage titer was measured as described in Section 2.5. The MOI resulting in the highest phage titer within $6 \mathrm{~h}$ was regarded as optimal MOI.

\section{One-step growth curve of phage}

First, $100 \mu \mathrm{L}$ of phages $\left(\sim 10^{8} \mathrm{PFU} / \mathrm{mL}\right)$ and their host bacteria $\left(\sim 10^{7} \mathrm{CFU} / \mathrm{mL}\right)$ were mixed and allowed to adsorb for $10 \mathrm{~min}$ at $37^{\circ} \mathrm{C}$. Here, the C. sakazakii strain of CICC 21560 was used as host for EspYZU01 and EspYZU02. The C. sakazakii strain of CICC 22919 was used as host for EspYZU03, EspYZU04, EspYZU05, EspYZU06, EspYZU07, EspYZU08, EspYZU09 and EspYZU10. The culture was centrifuged at $5,000 \times \mathrm{g}$ for $30 \mathrm{~s}$ at $4^{\circ} \mathrm{C}$. The pelleted cells were washed twice with pre-warmed nutrient broth, resuspended in $5 \mathrm{~mL}$ of nutrient broth, and incubated at $37^{\circ} \mathrm{C}$. The bacteriophage titer was determined by double agar plate method. The samples were taken every $10 \mathrm{~min}$ in $0-2 \mathrm{~h}$ and every $15 \mathrm{~min}$ in $2-4$ hours. A one-step growth curve was drawn with phage processing time as the abscissa and phage titer as the ordinate. During the incubation period, the burst size was calculated by the ratio of the final count of released phage particles to the initial count of infected bacterial cells.

\section{Genome sequencing and analysis}

\section{DNA extraction and purification}

The DNA extraction steps are the same as provided in the instructions of Ezup Spin Column Super Plant Genomic DNA Extraction Kit (Sangon Biotech, Shanghai, China). Briefly, first, $500 \mu \mathrm{L}$ of purified phages was mixed with $20 \mu \mathrm{L}$ of $500 \mathrm{mmol} / \mathrm{L}$ ethylenediaminetetra acetic acid, $30 \mu \mathrm{L}$ of $10 \% \mathrm{SDS}$, and $3 \mu \mathrm{L}$ of $10 \mathrm{mg} / \mathrm{mL}$ proteinase $\mathrm{K}$ and incubated at $56^{\circ} \mathrm{C}$ for $1 \mathrm{~h}$. Isovolumetric chloroform:isoamyl alcohol:phenol (25:24:1) mixture was added, mixed thoroughly, and centrifuged at $12,000 \times \mathrm{g}$ for $5 \mathrm{~min}$ at $4^{\circ} \mathrm{C}$. The upper layer was carefully transferred to a new sterile tube. This step was repeated using equal volumes of chloroform:isoamyl alcohol (24:1) mixture, which was centrifuged at $12,000 \times \mathrm{g}$ for $5 \mathrm{~min}$ at $4^{\circ} \mathrm{C}$. After incubation at $-20^{\circ} \mathrm{C}$ for $1 \mathrm{~h}$, DNA was precipitated from the solution with isopropanol. The solution was centrifuged at $4^{\circ} \mathrm{C}$ at $12,000 \times \mathrm{g}$ for $10 \mathrm{~min}$, and the supernatant was separated. The precipitate was washed twice with $70 \%$ ethanol, dried at room temperature, resuspended in 20- $\mu \mathrm{L}$ TE buffer ( $\mathrm{pH} 7.4$ ), and dissolved at $37^{\circ} \mathrm{C}$ for $30 \mathrm{~min}$. The quality and quantity of DNA was evaluated by GeneQuant (Eppendorf, Germany) and by running DNA on an agarose gel by electrophoresis followed by visualization.

\section{Genome sequencing and annotation}

The genomic DNA of phage was sequenced by Novogene Biology Information Technology Co. Ltd. (Beijing, China). A polymerase chain reaction (PCR)-free sequencing library of inserts of approximately 500 bp was constructed, and the Illumina $\mathrm{HiSeq}^{\mathrm{TM}} 2000$ sequencing platform was used for sequencing. The obtained raw sequencing data were filtered, and sequences containing the linker, primer, and low-quality data were removed. The clean data were used for subsequent analysis. The phage genome sequence was assembled using 
the SOAPdenovo software, and assembly conditions were adjusted to obtain the best stitching results. The amino acid sequences of the target species were compared with non-redundant (NR) database, and blast technology was used to locate the target species' genes and their corresponding functional annotation information (https://blast.ncbi.nlm.nih.gov/Blast.cgi). Given that each sequence may have more than one alignment, an optimal alignment result was retained as an annotation for the gene in order to ensure its biological significance. Homology alignment of the target and reference genomes was performed using the MUMmer software. A genome-wide map of phage was constructed using CGView (http://wishart.biology.ualberta.ca/cgview/).

\section{Application of phages}

\section{Preparation of phage cocktail}

The method for preparing phage cocktail is as follows: 1 - $\mathrm{mL}$ phage suspension with a titer of $\sim 10^{8} \mathrm{PFU} / \mathrm{mL}$ is mixed, and then stored at $4{ }^{\circ} \mathrm{C}$ until take into use. Phage cocktail-1 contains EspYZU01 and EspYZU05; cocktail-2 contains EspYZU02, EspYZU03, and EspYZU07; and cocktail-3 contains EspYZU01, EspYZU03, EspYZU08, EspYZU09, and EspYZU10. The C. sakazakii cocktail was prepared by mixing $1 \mathrm{~mL}$ of each host bacteria at a concentration of $\sim 10^{7} \mathrm{PFU} / \mathrm{mL}$, and used immediately.

\section{Application of phage against $\mathrm{C}$. sakazakii in nutrient broth}

First, $100 \mu \mathrm{L}$ of phage cocktail or EspYZU08 $\left(\sim 1 \times 10^{8}\right.$ $\mathrm{PFU} / \mathrm{mL}$ ) was mixed with $100 \mu \mathrm{L}$ of $C$. sakazakii cocktail $\left(\sim 1 \times 10^{7} \mathrm{CFU} / \mathrm{mL}\right)$. The mixture was then inoculated into $4.8 \mathrm{~mL}$ of nutrient broth and cultured at $37^{\circ} \mathrm{C}, 25^{\circ} \mathrm{C}$, and $4^{\circ} \mathrm{C}$ with continuous shaking at a speed of $120 \mathrm{rpm} / \mathrm{min}$. Optical density values at $600 \mathrm{~nm}\left(\mathrm{OD}_{600 \mathrm{~nm}}\right)$ were measured every $3 \mathrm{~h}$ at $25^{\circ} \mathrm{C}$ and $37^{\circ} \mathrm{C}$ and every $24 \mathrm{~h}$ at $4^{\circ} \mathrm{C}$. Nutrient broth containing $100 \mu \mathrm{L}$ of SM buffer instead of bacteriophage served as a positive control. All analyses were performed in triplicate.

\section{Application of phage against $\mathrm{C}$. sakazakii in milk}

Phage cocktail or EspYZU08 $\left(\sim 1 \times 10^{8} \mathrm{PFU} / \mathrm{mL}\right)$, $5 \mathrm{~mL}$, was mixed with $5 \mathrm{~mL}$ of $C$. sakazakii cocktail $\left(\sim 1 \times 10^{7} \mathrm{CFU} / \mathrm{mL}\right)$, which was mixed by five strains of CICC 21560, CICC 21545, CICC 21569, CICC 21673, and CICC 22919 in the same ratio. The mixture was then inoculated into $40 \mathrm{~mL}$ of milk and incubated at $37^{\circ} \mathrm{C}, 25^{\circ} \mathrm{C}$, and $4^{\circ} \mathrm{C}$ with continuous shaking at a speed of $120 \mathrm{rpm} / \mathrm{min}$. Standard plate count was performed on nutrient agar every $3 \mathrm{~h}$ at $25^{\circ} \mathrm{C}$ and $37^{\circ} \mathrm{C}$ and every $24 \mathrm{~h}$ at $4^{\circ} \mathrm{C}$ to quantify surviving cells. Milk containing $5 \mathrm{~mL}$ of SM buffer instead of bacteriophage was used as a positive control. All experiments were carried out in triplicate, and the bacterial concentration was expressed as mean $\mathrm{CFU} / \mathrm{mL}$ count and standard deviation.

\section{Results}

\section{Isolation and purification of phages}

A total of 10 phages infecting C. sakazakii strains were isolated from human stool and sewage samples and were marked as EspYZU01-EspYZU10. All 10 phages formed visible and uniform size plaques on the host strain (Figure 1A). Among these 10 phages, EspYZU01, EspYZU02, EspYZU06, EspYZU07, EspYZU08, EspYZU09, and EspYZU10 formed clear plaques of $0.5-1 \mathrm{~mm}$ in diameter. EspYZU03 and EspYZU04 formed blurry plaques of approximately $1 \mathrm{~mm}$ in diameter, and EspYZU05 formed a clear plaque of approximately $4 \mathrm{~mm}$ in diameter.

The phages were then purified and collected by discontinuous Cesium chloride $(\mathrm{CsCl})$ density gradient centrifugation. A visible bacteriophage band of $1.45-1.50 \mathrm{~g} / \mathrm{mL}$ $\mathrm{CsCl}$ was obtained with a titer of $10^{10}-10^{11} \mathrm{PFU} / \mathrm{mL}$.

\section{Morphology of phages}

Phage morphology was characterized by transmission electron microscopy (TEM). The results showed that 10 Cronobacter phages exhibited four types of morphology (Figure 1B). EspYZU01 and EspYZU09 had an elongated polyhedron head with a diameter of $\sim 70 \mathrm{~nm} \times 120$ $\mathrm{nm}(\mathrm{L} / \mathrm{W}=1.7)$ and a tail length of $\sim 120 \mathrm{~nm}$, indicating that the phages belonged to the Myoviridae family. EspYZU02 and EspYZU08 had an isometric polyhedron head with a diameter of $\sim 90 \mathrm{~nm}$, tail length of $\sim 120 \mathrm{~nm}$, and a contractile tail sheath, indicating that the phages also belonged to the Myoviridae family. EspYZU03, EspYZU04, and EspYZU07 had an isometric polyhedron head but without tail sheath, indicating that the phages also belonged to the Myoviridae family. EspYZU05 had an isometric polyhedron head with a diameter of $\sim 55 \mathrm{~nm}$ and a tail length of $\sim 18 \mathrm{~nm}$, indicating that the phages belonged to the Podoviridae family. EspYZU06 had an isometric polyhedron head with a diameter of $\sim 60 \mathrm{~nm}$ but without a tail, indicating that the phages belonged to the Tectivirus family. EspYZU10 had an isometric polyhedron head with a diameter of $\sim 130 \mathrm{~nm}$ and a tail length of $\sim 250 \mathrm{~nm}$ but without tail sheath, indicating that the phages belonged to the Stylovinidae family.

\section{Host range of phage}

The results of host range of phages are listed in Table 1. EspYZU02 had the highest specificity and could only infect the CICC 21560 strain. EspYZU08 had the broadest infection spectrum and could infect all five C. sakazakii strains. The eight other phages could infect two to four C. sakazakii strains (Table 1). 


\section{Characterization of phages}

\section{Effect of temperature and $\mathrm{pH}$ on phage infectivity}

The effect of temperature on phage infectivity was tested by exposing phages to a range of different extreme temperatures. When the phages were exposed to $50^{\circ} \mathrm{C}$ for $1 \mathrm{~h}$, infectivity retained by all phages was quite well. At $60^{\circ} \mathrm{C}$ for $1 \mathrm{~h}$, the infectivity of EspYZU01, EspYZU07,
EspYZU08, and EspYZU10 declined slightly $(<20 \%)$; that of EspYZU02, EspYZU03, EspYZU04, and EspYZU6 declined by 20-44.8\%; and that of EspYZU05 and EspYZU9 declined by $>50 \%$. At $70^{\circ} \mathrm{C}$, phage infectivity declined sharply. EspYZU01, EspYZU02, EspYZU04, and EspYZU5 lost their infectivity after $40 \mathrm{~min}$; EspYZU03 and EspYZU9 lost their infectivity after $20 \mathrm{~min}$; and only EspYZU06, EspYZU07, EspYZU08, and EspYZU10
(A)

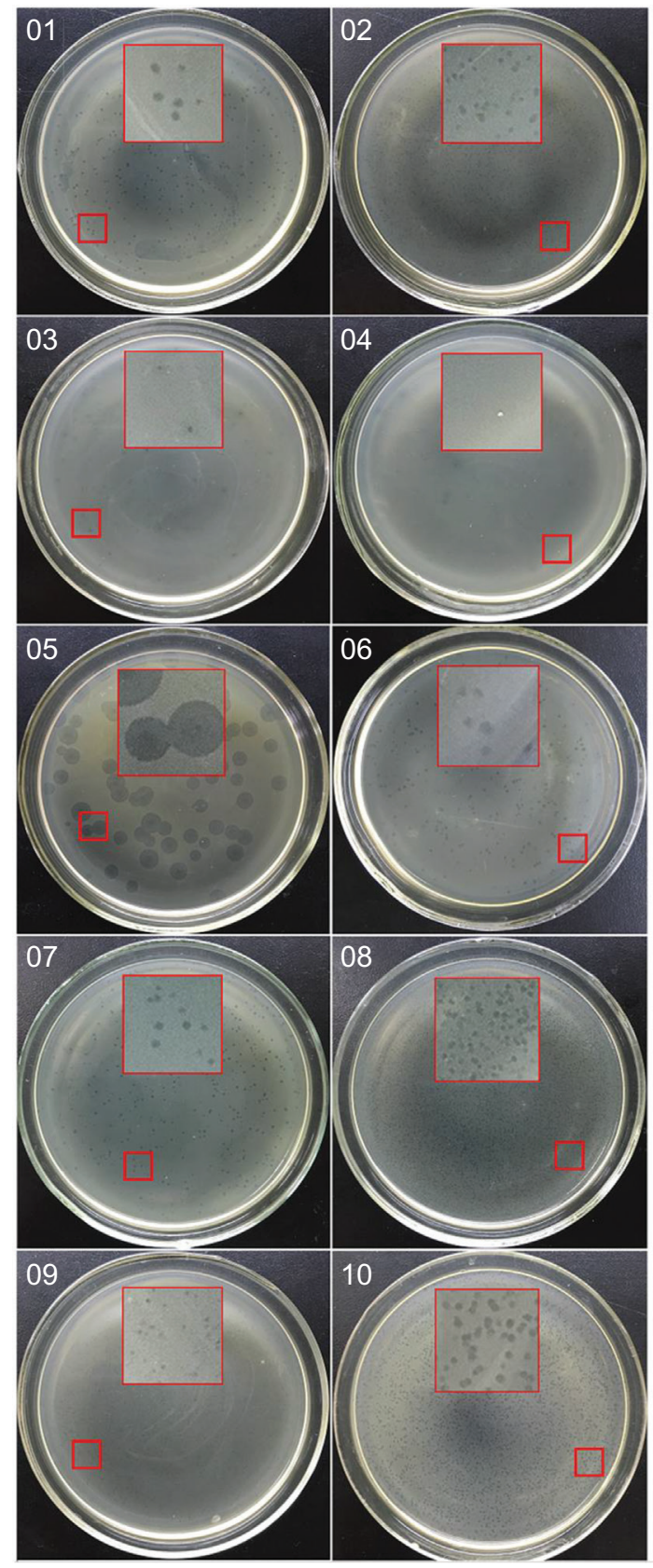

(B)

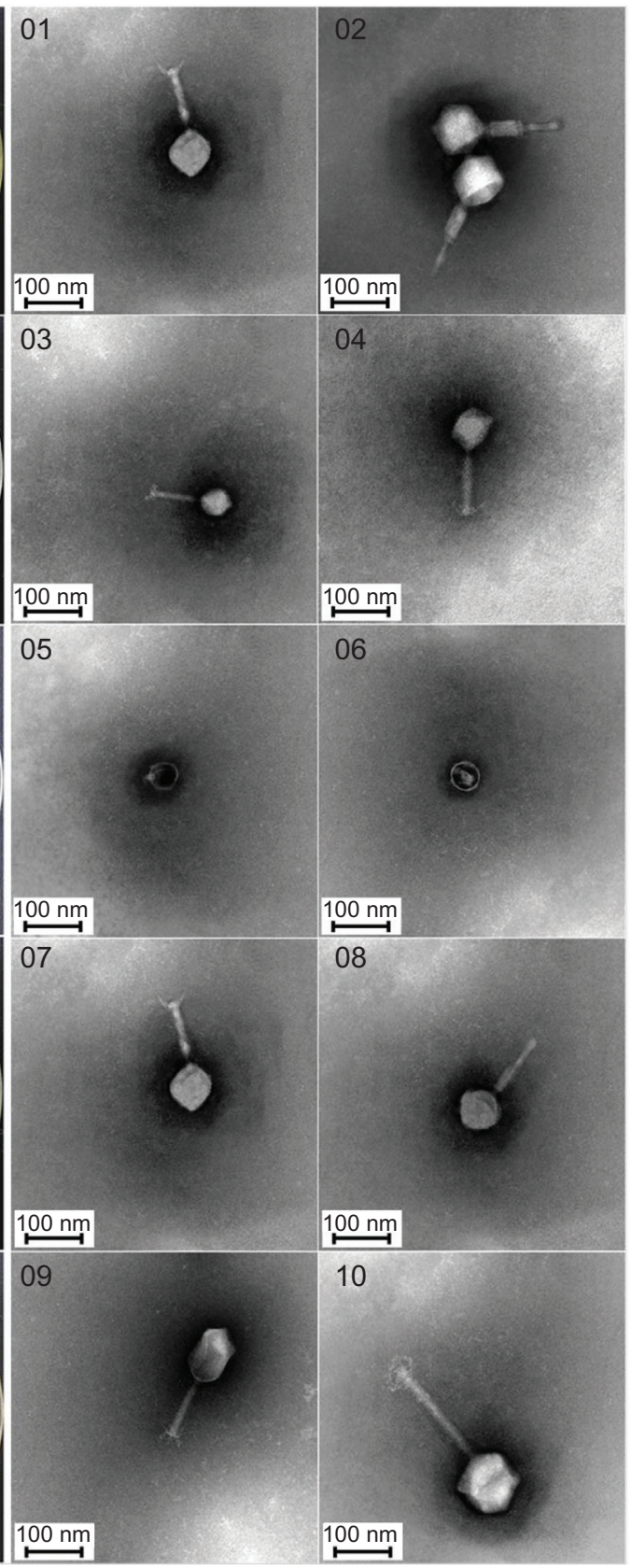

Figure 1. Characterization of (A) plaque and (B) microscopic morphological features of Cronobacter sakazakii phages. 01: EspYZU01; 02: EspYZU02; 03: EspYZU03; 04: EspYZU04; 05: EspYZU05; 06: EspYZU06; 07: EspYZU07; 08: EspYZU08; 09: EspYZU09; 10: EspYZU10. (A) Images of phage plaques are magnified four times and shown with red squares. (B) Morphology and dimensions of phages were examined with a Tecnai-12 transmission electron microscope. 
Table 1. Host range of Cronobacter sakazakii phages.

\begin{tabular}{|c|c|c|c|c|c|c|c|c|c|c|c|}
\hline \multirow[t]{2}{*}{ Host species } & \multirow[t]{2}{*}{ Strain } & \multicolumn{10}{|c|}{ Lysis by bacteriophages } \\
\hline & & 01 & 02 & 03 & 04 & 05 & 06 & 07 & 08 & 09 & 10 \\
\hline Cronobacter sakazakii & CICC 21560 & + & + & - & - & - & - & - & + & + & - \\
\hline Cronobacter sakazakii & CICC 21545 & + & - & + & + & + & - & + & + & - & + \\
\hline Cronobacter sakazakii & CICC 21569 & - & - & + & - & + & + & + & + & - & + \\
\hline Cronobacter sakazakii & CICC 21673 & + & - & + & + & + & - & + & + & + & - \\
\hline Cronobacter sakazakii & CICC 22919 & - & - & + & + & + & + & + & + & + & + \\
\hline Cronobacter sakazakii & CsYZ-01 & - & - & - & - & + & - & - & + & - & + \\
\hline Cronobacter sakazakii & CsYZ-04 & - & - & + & + & + & + & + & + & + & + \\
\hline Cronobacter sakazakii & CsYZ-06 & - & - & - & - & + & - & - & + & - & - \\
\hline Cronobacter turicensis & CtYZ-03 & - & - & - & - & - & - & - & - & - & - \\
\hline Cronobacter malonaticus & CmYZ-01 & - & - & - & - & - & - & - & - & - & - \\
\hline Enterobacter cloacae & CICC10017 & - & - & - & - & - & - & - & - & - & - \\
\hline Enterobacter cloacae & EcY02 & - & - & - & - & - & - & - & - & - & - \\
\hline Enterobacter cloacae & EcY05 & - & - & - & - & - & - & - & - & - & - \\
\hline Escherichia coli & EcJ01 & - & - & - & - & - & - & - & - & - & - \\
\hline Escherichia coli & EcJ05 & - & - & - & - & - & - & - & - & - & - \\
\hline Escherichia coli & EcJ07 & - & - & - & - & - & - & - & - & - & - \\
\hline Enterobacter hormaechei & SYZU2-5 & - & - & - & - & - & - & - & - & - & - \\
\hline Pseudomonas fluorescens & Pf5401 & - & - & - & - & - & - & - & - & - & - \\
\hline Pseudomonas fluorescens & Pf5502 & - & - & - & - & - & - & - & - & - & - \\
\hline Pseudomonas fluorescens & Pf5507 & - & - & - & - & - & - & - & - & - & - \\
\hline Pseudomonas fluorescens & Pf5608 & - & - & - & - & - & - & - & - & - & - \\
\hline Klebsiella pneumoniae & KpJ08 & - & - & - & - & - & - & - & - & - & - \\
\hline Klebsiella pneumoniae & KpJ06 & - & - & - & - & - & - & - & - & - & - \\
\hline Klebsiella pneumoniae & KpJ05 & - & - & - & - & - & - & - & - & - & - \\
\hline Klebsiella pneumoniae & KpJ03 & - & - & - & - & - & - & - & - & - & - \\
\hline Bacillus subtilis & BsJ01 & - & - & - & - & - & - & - & - & - & - \\
\hline Bacillus subtilis & BsJ02 & - & - & - & - & - & - & - & - & - & - \\
\hline Bacillus subtilis & BsJ05 & - & - & - & - & - & - & - & - & - & - \\
\hline Bacillus subtilis & BsJ07 & - & - & - & - & - & - & - & - & - & - \\
\hline Bacillus subtilis & BsJ08 & - & - & - & - & - & - & - & - & - & - \\
\hline Number of hosts & & 3 & 1 & 5 & 4 & 7 & 3 & 5 & 8 & 4 & 5 \\
\hline
\end{tabular}

Note: 01: EspYZU01; 02: EspYZU02; 03: EspYZU03; 04: EspYZU04; 05: EspYZU05; 06: EspYZU06; 07: EspYZU07; 08: EspYZU08; 09: EspYZU09; 10: EspYZU10.

+: having lytic activity; -: having no lytic activity.

retained $22.1-41.7 \%$ of their infectivity after $1 \mathrm{~h}$ (Figure 2A). The results indicated that EspYZU07, EspYZU08, and EspYZU10 have the best thermal stability.

The effect of $\mathrm{pH}$ on phage infectivity was tested by exposing phages to $\mathrm{pH}$ ranging from 3.0 to 11 for $2 \mathrm{~h}$ at $37^{\circ} \mathrm{C}$. The infectivity retained by all phages was quite well if they were exposed to an environment having $\mathrm{pH}$ 5.0-9.0 but declined sharply at $\mathrm{pH}<5.0$. At $\mathrm{pH}<4$ or $>10$, EspYZU01, EspYZU06, EspYZU07, EspYZU08, and EspYZU10 retained their high infectivity. Good infectivity of EspYZU03, EspYZU04, EspYZU05, and EspYZU09 
was retained in alkaline environment $(\mathrm{pH}=7-10)$ but declined sharply at $\mathrm{pH}<4$ (Figure $2 \mathrm{~B}$ ). The results indicated that EspYZU01, EspYZU06, EspYZU07, EspYZU08, and EspYZU10 had the best $\mathrm{pH}$ stability.

\section{Optimal multiplicity of infection (MOI) of phages}

The MOI of all phages were determined as described in Section 2.10, and the results are listed in Table 2. EspYZU02, EspYZU03, and EspYZU04 had the maximal MOI of 10, and EspYZU06 and EspYZU10 showed the minimum MOI of 0.001 .

One-step growth curves of phages were obtained by propagation on C. sakazakii at $37^{\circ} \mathrm{C}$ (Figure 3). The latent periods of phages occurred from 10 to $45 \mathrm{~min}$. The rising period began with average burst size of 65-439 phage particles per bacterium (Table 3). Among the phages, EspYZU09 had the shortest latent period of $10 \mathrm{~min}$, and EspYZU06 showed the longest latent period of $45 \mathrm{~min}$. EspYZU10 had the maximal burst size of 439, and EspYZU08 demonstrated the second maximal burst size of 366 .

\section{Genome analysis of phage}

Among the phages, EspYZU05 and EspYZU08 infected the same host of CICC 21569 and showed broad host range. However, they presented remarkably different
(A)

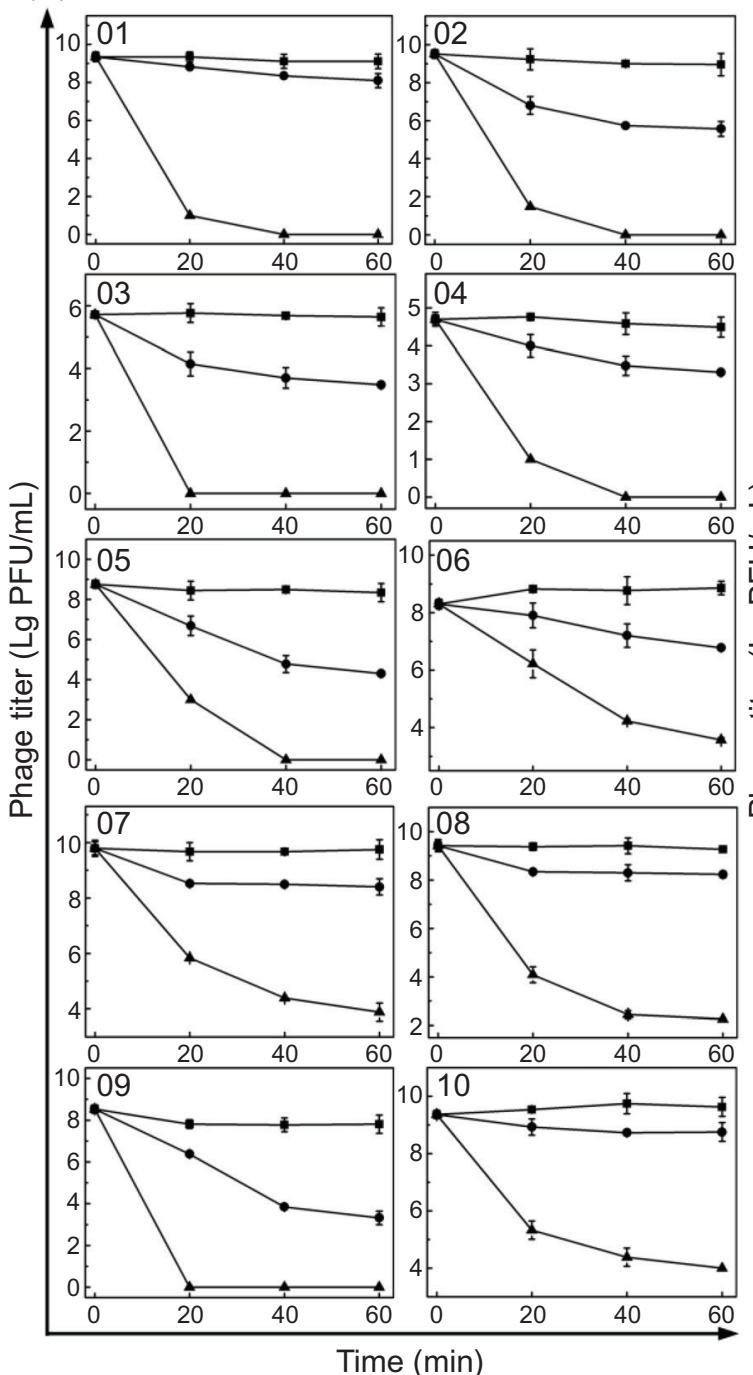

(B)

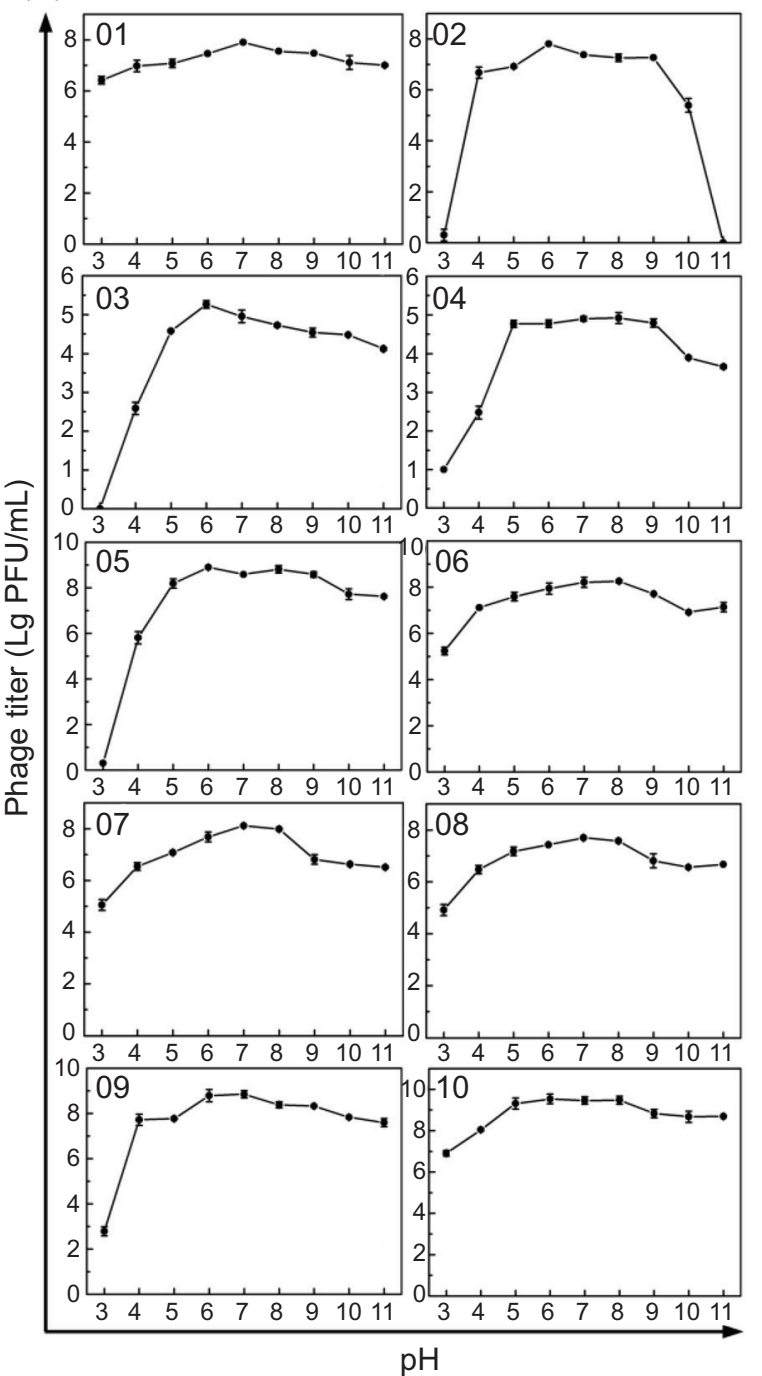

Figure 2. Effects of $(A)$ temperature and $(B) \mathrm{pH}$ on phage infectivity. 01: EspYZU01; 02: EspYZU02; 03: EspYZU03; 04: EspYZU04; 05: EspYZU05; 06: EspYZU06; 07: EspYZU07; 08: EspYZU08; 09: EspYZU09; 10: EspYZU10; (A) The effect of temperature on the viability of phage in nutrient broth at $50-70^{\circ} \mathrm{C}$ for $20-60 \mathrm{~min} .(\bullet),(\square)$, and $(\boldsymbol{\Delta})$, respectively, represent the infectivity of phage exposed at $50^{\circ} \mathrm{C}$ for $20-60 \mathrm{~min}, 60^{\circ} \mathrm{C}$ for $20-60 \mathrm{~min}$, and $70^{\circ} \mathrm{C}$ for $20-60 \mathrm{~min}$. (B) The effect of $\mathrm{pH}$ on the viability of phage in nutrient broth at $\mathrm{pH} 3-11$ and $37^{\circ} \mathrm{C}$ for $2 \mathrm{~h}$. Each assay was conducted in triplicate, and the values were expressed as mean \pm standard deviation. 
morphologies; hence, we sequenced and analyzed the whole genomes of EspYZU05 and EspYZU08. The genome of EspYZU05 was obtained with a size of $41723 \mathrm{bp}, \mathrm{G}+\mathrm{C}$ content of $55.69 \%$, gene coding percentage of $93.04 \%$, and open reading frames (ORFs) of 47 (Figure 4A). The genome data of EspYZU05 was deposited in GenBank under the accession number MW882933; annotation of ORFs is shown in Table S1 provided in supplementary material. The genome of EspYZU08 with a size of 145582 bp, $\mathrm{G}+\mathrm{C}$ content of $46.76 \%$, gene coding percentage of $42.03 \%$, and ORF of 103 was obtained (Figure 4B). The genome data of EspYZU08 was deposited in GenBank under the accession number MW882934; annotation of ORFs is shown in Table S2 provided in supplementary material. Genomes of both EspYZU05 and EspYZU08 were double-stranded DNAs, and no tRNA gene was analyzed. Regarding the similarity of phage proteins with those from the NCBI database, the genome of EspYZU05 was found to be highly similar to that of C. sakazakii phage vB_CskP_GAP227 (KC107834.1), with 96\% identity and 98\% coverage rate. The genome of EspYZU08 was very similar to Salmonella phage PVP-SE1 (GU070616.1) with $97 \%$ identity and $82 \%$ coverage rate.

Table 2. The optimum multiplicity of infection (MOI) of phages.

\begin{tabular}{lccc} 
Phage & MOI & $\begin{array}{c}\text { Phage/Host } \\
\text { (CFU/mL) }\end{array}$ & $\begin{array}{c}\text { Titer } \\
\text { (PFU/mL) }\end{array}$ \\
\hline EspYZU01 & 0.1 & $\left(10^{4} / 10^{5}\right)$ & $5.6 \times 10^{10}$ \\
EspYZU02 & 10 & $\left(10^{6} / 10^{5}\right)$ & $2.1 \times 10^{10}$ \\
EspYZU03 & 10 & $\left(10^{6} / 10^{5}\right)$ & $2.3 \times 10^{4}$ \\
EspYZU04 & 10 & $\left(10^{6} / 10^{5}\right)$ & $1.09 \times 10^{4}$ \\
EspYZU05 & 1 & $\left(10^{5} / 10^{5}\right)$ & $2.35 \times 10^{11}$ \\
EspYZU06 & 0.001 & $\left(10^{2} / 10^{5}\right)$ & $8.7 \times 10^{10}$ \\
EspYZU07 & 0.1 & $\left(10^{4} / 10^{5}\right)$ & $1.97 \times 10^{9}$ \\
EspYZU08 & 0.1 & $\left(10^{4} / 10^{5}\right)$ & $1.62 \times 10^{9}$ \\
EspYZU09 & 1 & $\left(10^{5} / 10^{5}\right)$ & $2.58 \times 10^{9}$ \\
EspYZU10 & 0.001 & $\left(10^{2} / 10^{5}\right)$ & $4.6 \times 10^{9}$ \\
\hline
\end{tabular}

Table 3. The lysis property of Cronobacter sakazakii phages.

\begin{tabular}{lcccc} 
Phage & Latent period $(\mathrm{min})$ & Burst period $(\mathrm{min})$ & Stable period $(\mathrm{min})$ & Burst size (phage particles per bacterium) \\
\hline EspYZU01 & $0-20$ & $20-80$ & After 80 & 65 \\
EspYZU02 & $0-30$ & $30-100$ & After 100 & 192 \\
EspYZU03 & $0-40$ & $40-100$ & After 100 & 112 \\
EspYZU04 & $0-20$ & $20-100$ & After 100 & 59 \\
EspYZU05 & $0-20$ & $20-180$ & After 180 & 135 \\
EspYZU06 & $0-40$ & $40-135$ & After 135 & 127 \\
EspYZU07 & $0-20$ & $20-150$ & After 150 & 33 \\
EspYZU08 & $0-40$ & $40-180$ & After 180 & 366 \\
EspYZU09 & $0-10$ & $10-110$ & After 110 & 215 \\
EspYZU10 & $0-40$ & $40-180$ & After 180 & 439 \\
\hline
\end{tabular}

The functional ORFs of phage genomes could be classified into structure (e.g., membrane protein, scaffolding protein, capsid/head protein, head-tail connector protein, tail tubular protein, minor tail protein, tail sheath protein, and tail attachment protein), packaging (e.g., ribonucleotide

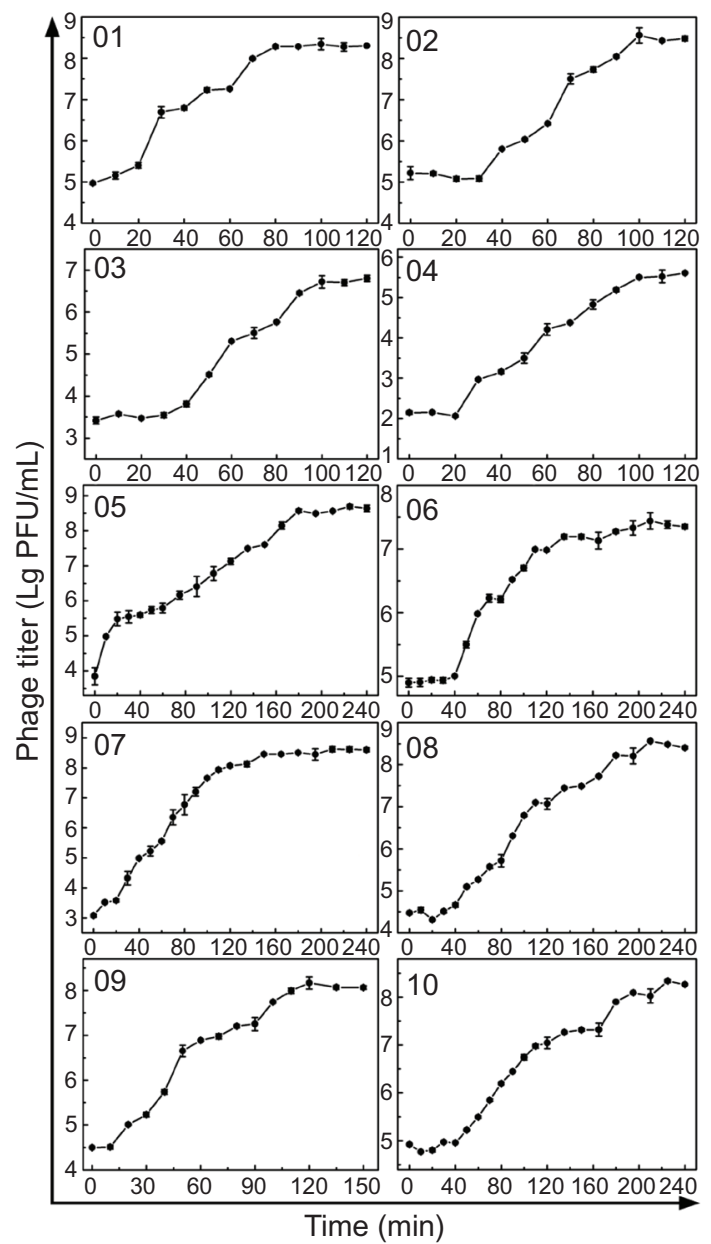

Figure 3. One-step growth curve of phages. 01: EspYZU01; 02: EspYZU02; 03: EspYZU03; 04: EspYZU04; 05: EspYZU05; 06: EspYZU06; 07: EspYZU07; 08: EspYZU08; 09: EspYZU09; 10: EspYZU10. Each assay was conducted in triplicate, and the values were expressed as mean \pm standard deviation. 

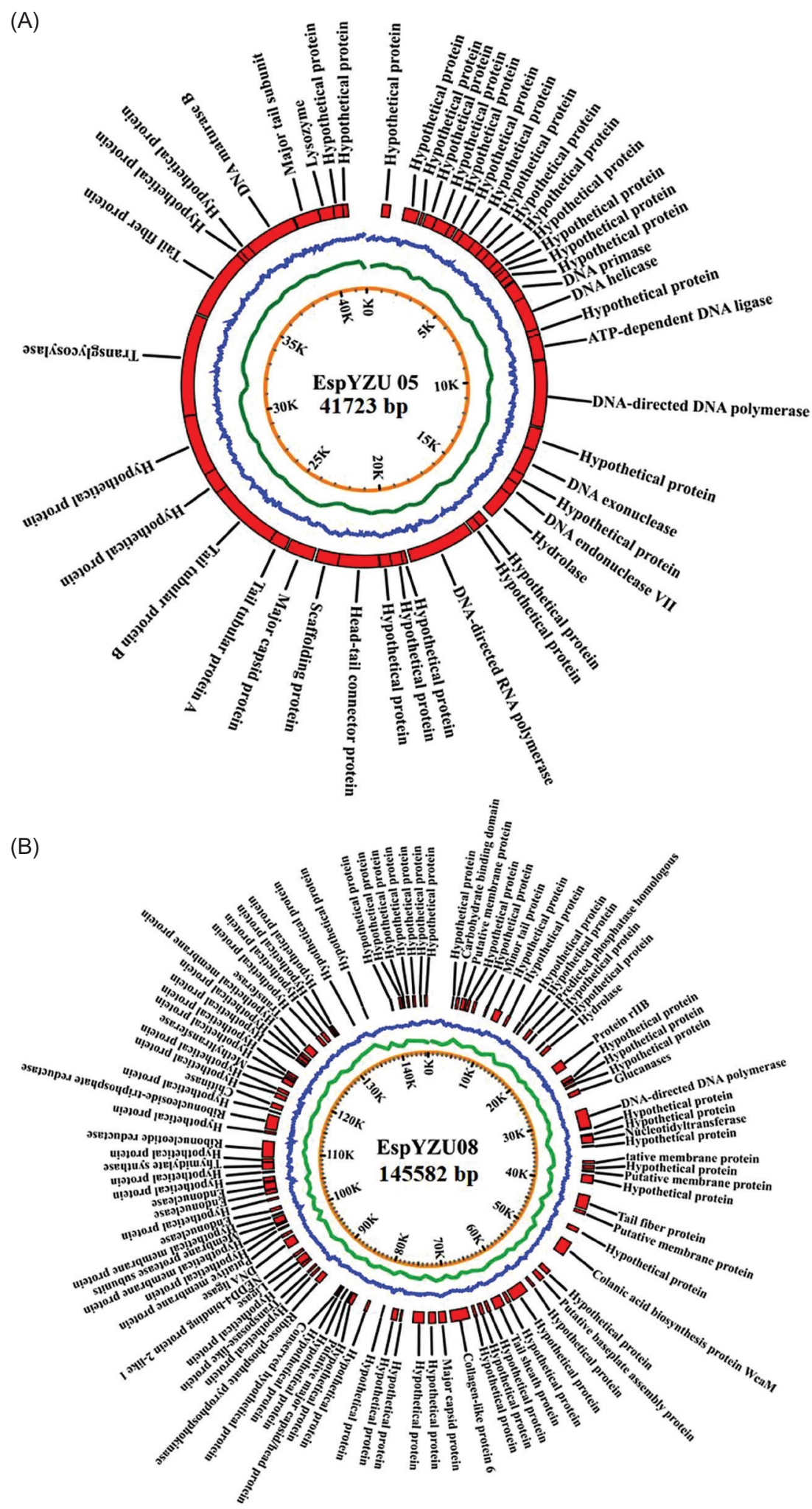

Figure 4. Genome pattern of phages EspYZU05 and EspYZU08. (A) Genome pattern of phage EspYZU05 (accession number is "MW882933"); (B) Genome pattern of phage EspYZU08 (accession number is "MW882934"). Circles display (from the outside): (1) ORFs transcribed in clockwise or counterclockwise direction; (2) $G+C \%$ content. Values $>42.97 \%$ (average) are outward peaks, and those $<42.97 \%$ are inward peaks; (3) $G C$ skew $(G-C / G+C$, in a 1-kb window and $0.1-\mathrm{kb}$ incremental shift). Values $>0$ are inward peaks, and those $<0$ are outward peaks; (4) Physical map is scaled in kbp (for interpretation of references to color in this figure, the reader is referred to the web version of this article). 
reductase), DNA manipulation (e.g., DNA helicases, DNA polymerase, DNA ligase, DNA primase, DNA maturase, and DNA exonuclease), transcription (e.g., RNA polymerase and RNA ligase), and additional functions (e.g., nicotinamide-nucleotide adenylyltransferase and transposase protein). Furthermore, some host lysis-related proteins were found, such as lytic glycosylase (ORF39) and endolysin (ORF45) in EspYZU05 and colanic acid degrading protein (ORF18) in EspYZU08, which contribute to infecting and lysing the host cell. However, many products of predicted ORFs in genomes remain hypothetical proteins, these may result from the insufficient annotation data of C. sakazakii bacteriophage genomes.
Furthermore, the safety of phages was assessed on the basis of genomes, and no gene for toxins and antibiotic resistance was detected.

\section{Bacterial challenge test of phage and cocktail in liquid broth}

In order to evaluate the best antibacterial efficacy of phages, we measured the infectivity of EspYZU08 and phage cocktails in liquid broth at different temperatures (Figure 5). Cocktail-3 (EspYZU01 + EspYZU03 + EspYZU08 + EspYZU09 + EspYZU10) could inhibit the

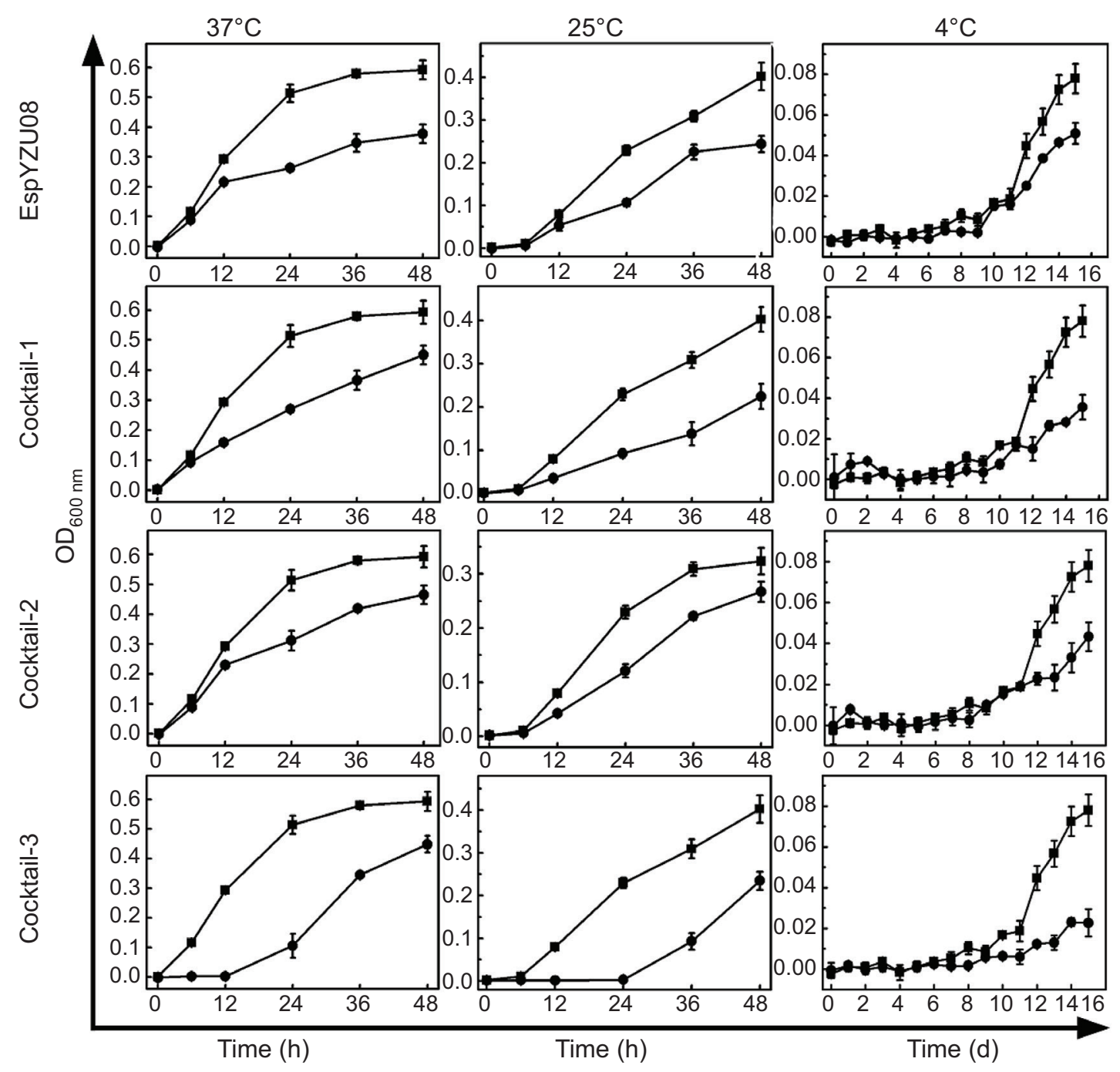

Figure 5. Growth inhibition of C. sakazakii using phage EspYZU08 or phage cocktail in nutrient broth at different temperatures. Cocktail-1: EspYZU01 + EspYZU05; cocktail2: EspYZU02 + EspYZU03 + EspYZU07; cocktail-3: EspYZU01 + EspYZU03 + EspYZU08 + EspYZU09 + EspYZU10. (口) represents C. sakazakii grown in the absence of phage; (๑) represents C. sakazakii grown in the presence of phage EspYZU08 or phage cocktail ( 1 $\left.\times 10^{8} \mathrm{PFU} / \mathrm{mL}\right)$. Growth inhibition of $C$. sakazakii was determined by CFU/mL counts. Each assay was conducted in triplicate, and the values were expressed as mean \pm standard deviation. 
growth of C. sakazakii for $12 \mathrm{~h}$ at $37^{\circ} \mathrm{C}, 24 \mathrm{~h}$ at $25^{\circ} \mathrm{C}$, and 12 days at $4{ }^{\circ} \mathrm{C}$. The inhibition ratio of $\mathrm{I}_{12}, \mathrm{I}_{24} \mathrm{~h}$, and $\mathrm{I}_{12 \mathrm{~d}}$ reached $99.20 \%, 98.69 \%$, and $72.40 \%$, respectively. Compared with other phages and cocktails, cocktail-3 presented the best antibacterial effect. Thus, cocktail-3 was used to further evaluate its antibacterial effect in food.

\section{Application of phage cocktail in milk}

In order to verify the potential of phages as a novel biocontrol agent against $C$. sakazakii in food, we used cocktail-3 (EspYZU01 + EspYZU03 + EspYZU08 + EspYZU09 + EspYZU10) with a titer of $\sim 1 \times 10^{8} \mathrm{PFU} / \mathrm{mL}$ to evaluate antibacterial effect in milk at different temperatures (Figure 6). After cocktail-3 was added, the total viable counts of C. sakazakii in milk decreased to the minimum value for $6 \mathrm{~h}$ at $37^{\circ} \mathrm{C}, 9 \mathrm{~h}$ at $25^{\circ} \mathrm{C}$, and 5 days at $4^{\circ} \mathrm{C}$ and reduced by $2.92 \mathrm{lg} \mathrm{CFU} / \mathrm{mL}, 2.97 \mathrm{lg} \mathrm{CFU} / \mathrm{mL}$, and $1.64 \mathrm{lg} \mathrm{CFU} / \mathrm{mL}$ compared with the initial values and by $4.57 \mathrm{lg} \mathrm{CFU} / \mathrm{mL}, 4.25 \mathrm{lg} \mathrm{CFU} / \mathrm{mL}$, and $3.43 \mathrm{lg}$ $\mathrm{CFU} / \mathrm{mL}$ compared with the control (no phage), respectively. In addition, addition of cocktail-3 significantly decreased the population of C. sakazakii $(\mathrm{P}<0.001)$ relative to the control within a certain time frame. This result suggested that cocktail-3 could remarkably inhibit growth of C. sakazakii in milk for $6 \mathrm{~h}$ at $37^{\circ} \mathrm{C}-9 \mathrm{~h}$ at $25^{\circ} \mathrm{C}$ and 5 days at $4^{\circ} \mathrm{C}$.

\section{Discussions}

C. sakazakii, generally found in contaminated infant milk formula powders, is a fatal food-borne pathogen with high mortality rates (Drudy et al., 2006). Bacteriophage is considered as an alternative and promising approach to control C. sakazakii in foods. In this study, we isolated and characterized 10 Cronobacter phages with host lysis activity from sewage and stool samples of patients suspected of C. sakazakii infection. Sewage is a primary niche for Enterobacteriaceae; thus, the isolation of Cronobacter phages from effluent environments is not uncommon (Kim et al., 2007; Zuber et al., 2008). After morphological observation through TEM, 10 phages were considered to belong to Myoviridae, Podoviridae, Tectivirus, and Siphoviridae families. The phage susceptibility was assessed using five C. sakazakii strains. EspYZU08 had the broadest host range because it infected all five strains. The broad host range capabilities of five combined C. sakazakii phages show an infection profile extending across several genera (Zuber et al., 2008). Thus, the C. sakazakii phage of EspYZU08 may have good application prospect to control multiple pathogens in food. In addition, given that phages EspYZU08 and EspYZU05 have lytic lifestyles and do not possess genes for toxic proteins, they meet the required properties of phages

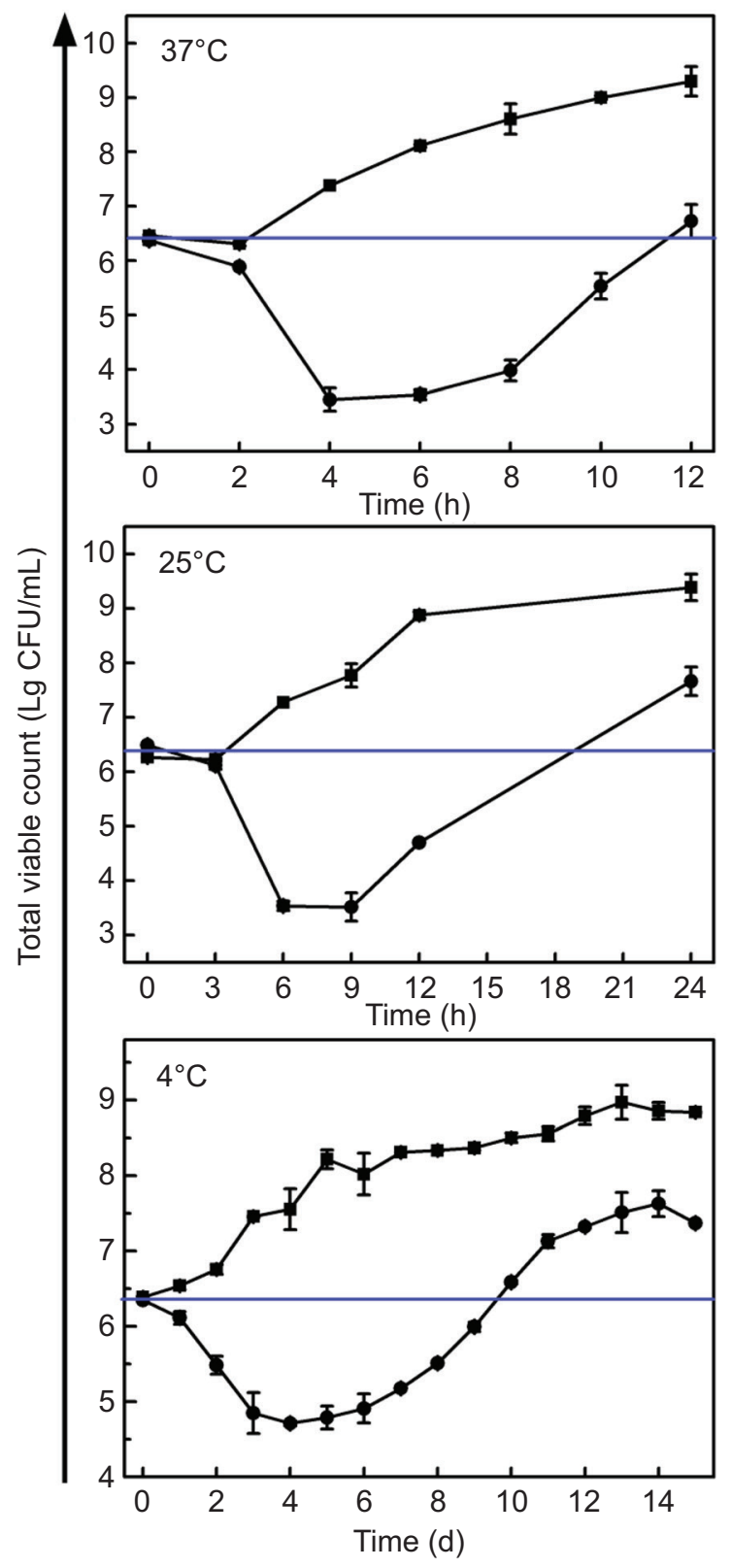

Figure 6. Growth inhibition of C. sakazakii using phage cocktail-3 in milk. Cocktail-3 was mixed with EspYZU01, EspYZU03, EspYZU08, EspYZU09, and EspYZU10. (घ) represents C. sakazakii grown in the absence of phage; $(\bullet)$ represents $C$. sakazakii grown in the presence of phage cocktail $\left(\sim 1 \times 10^{8} \mathrm{PFU} / \mathrm{mL}\right)$. Growth inhibition of $C$. sakazakii was determined by $\mathrm{CFU} / \mathrm{mL}$ counts. Assays were performed in triplicate and bacterial concentrations were expressed as mean \pm standard deviation.

intended for biocontrol applications. Although a transpose was found in phage EspYZU08, the transpose was proved to be safe for human cells and even could be used for clinical trial (Magnani et al., 2018; Zhang et al., 2021).

Environmental stability is essential for phages to be used as a biocontrol in foods. The common environmental 
pressure includes low $\mathrm{pH}$ and high temperature. The environmental stability of 10 phages was tested. It was found that all phages retained their maximum infectivity after exposure to $\mathrm{pH}$ ranging from 5 to 9 , but their infectivity declined sharply at $\mathrm{pH}<5$. The $\mathrm{pH}$ stability of these phages was similar to some other C. sakazakii phages. C. sakazakii phages leB, leE, and leN retain their activity after exposure to $\mathrm{pH} 6-10$, but no viable phages could be observed when exposure to both $\mathrm{pH}=2$ and 4 for $1 \mathrm{~h}$ (Endersen et al., 2017). The C. sakazakii phage PBES 02 also retained its infectivity after exposure to $\mathrm{pH}=6-10$, but its infectivity decreased at $\mathrm{pH}<5$ (Lee et al., 2016b). However, some phages have very high $\mathrm{pH}$ stability, such as coliphage $\lambda$, which shows no remarkable decrease in titer at $\mathrm{pH}=3-11$ (Jepson and March, 2004).

Temperature also plays a fundamental role in the survival of phages. High optimal temperatures are thought to extend the latent period, whereas low optimal temperatures are often thought to result in reduced multiplication rate (Tey et al., 2009). In this study, phages retained their infectivity at $50^{\circ} \mathrm{C}$ and showed slightly decreased infectivity at $60^{\circ} \mathrm{C}$ following a 1 - $\mathrm{h}$ challenge. However, at $70^{\circ} \mathrm{C}$, many phages were inactivated following incubation for $1 \mathrm{~h}$. The thermostability of these phages was also similar to that of some other $C$. sakazakii phages. The C. sakazakii phages leB, leE, and leN retained their infectivity between $4^{\circ} \mathrm{C}$ and $50^{\circ} \mathrm{C}$, and no viable phages could be recovered from the lysates exposed to $60^{\circ} \mathrm{C}, 72^{\circ} \mathrm{C}$, or $90^{\circ} \mathrm{C}$ for $1 \mathrm{~h}$ (Endersen et al., 2017). The infectivity of C. sakazakii phage PBES 02 is retained after exposure to $4-55^{\circ} \mathrm{C}$ for $1 \mathrm{~h}$ but decreased sharply (75\% lost) at $>65^{\circ} \mathrm{C}$ for $1 \mathrm{~h}$ (Lee et al., 2016b).

Clarifying the genomic information of each bacteriophage is essential to ensure the specificity and safety (without virulence factors) of bacteriophage as a biological therapeutic agent (Brüssow et al., 2004; Faruque and Mekalanos, 2012). Besides, genome sequencing helps to further understand the phage-host interactions and provide necessary information to further exploit their biological therapeutic properties. Thus, the genomes of EspYZU05 and EspYZU08 were sequenced and analyzed, and no gene for toxins and antibiotic resistance was detected. However, some endolysin-supporting proteins were found, such as lytic glycosylase, endolysin, and colanic acid-degrading protein, which support the infection and lysis of host cell.

In this study, the lysis activity of these phages for food application was demonstrated using phage cocktail $\left(\sim 1 \times 10^{8} \mathrm{PFU} / \mathrm{mL}\right)$ against $C$. sakazakii $\left(\sim 1 \times 10^{7}\right.$ $\mathrm{CFU} / \mathrm{mL})$ in milk. The results showed that cocktail-3 $($ EspYZU01 + EspYZU03 + EspYZU08 + EspYZU09 + EspYZU10) presented the best efficacy and controlled C. sakazakii for $6 \mathrm{~h}$ at $37^{\circ} \mathrm{C}, 9 \mathrm{~h}$ at $25^{\circ} \mathrm{C}$, and 5 days at $4^{\circ} \mathrm{C}$. Relative to initial values, the population of $\mathrm{C}$. sakazakii was reduced by $2.92 \mathrm{lg} \mathrm{CFU} / \mathrm{mL}(44.92 \%)$ at $37^{\circ} \mathrm{C}$, $2.97 \mathrm{lg} \mathrm{CFU} / \mathrm{mL}(45.69 \%)$ at $25^{\circ} \mathrm{C}$, and $1.64 \mathrm{lg} \mathrm{CFU} / \mathrm{mL}$ $(25.23 \%)$ at $4^{\circ} \mathrm{C}$. The Cronobacter phages leB, leE, and leN were combined as a part of phage cocktail $\left(\sim 3 \times 10^{8}\right.$ $\mathrm{PFU} / \mathrm{mL}$ ) to assess their ability to inhibit the growth of C. sakazakii $\left(\sim 1 \times 10^{4} \mathrm{CFU} / \mathrm{mL}\right)$ in four different brands of infant formula. The C. sakazakii concentrations were reduced to below the detection limit $(<10 \mathrm{CFU} / \mathrm{mL})$ in 5 -h incubation when challenged with phage cocktail, and this level of inactivation was maintained over the 20-h challenge (Endersen et al., 2017). The Cronobacter phage CR5 at an MOI of $10^{5}$ was added to a sample containing C. sakazakii, and the bacterial strain was lysed at $2 \mathrm{~h}$ and never recovered up to $10 \mathrm{~h}$ (Lee et al., 2016a). When the Cronobacter phage PBES 02 with an MOI of $10^{5}$ was added to infant formula containing C. sakazakii, the bacteria were completely eliminated in $6 \mathrm{~h}$ (Lee et al., 2016b). The Cronobacter phage Dev2 completely killed the bacteria at a high initial MOI $\left(10^{2} \mathrm{CFU} / \mathrm{mL}\right.$ bacteria and $10^{8} \mathrm{PFU} / \mathrm{mL}$ phages) in LB medium and reconstituted milk formula; similar results were observed at $20^{\circ} \mathrm{C}$, $30^{\circ} \mathrm{C}$, and $37^{\circ} \mathrm{C}$ (Kajsík et al., 2014).

In general, we used a low MOI of 10, and the biocontrol results were similar to those of some other C. sakazakii phages. The level of C. sakazakii contamination in powdered infant formula is very low ( $<1$ bacterial cell/100 g) (Holý and Forsythe, 2014). However, the contaminating levels of C. sakazakii used in this study were much higher than those typically found in powdered infant formula, demonstrating the efficacy of this phage cocktail to be explored further.

\section{Conclusions}

A total of 10 Cronobacter phages (EspYZU01-EspYZU10) were isolated from sewage and human stool samples. After morphological observation and characterization, the genomes of phages EspYZU05 and EspYZU08 were analyzed, and no toxins and antibiotic resistance genes were detected. The phage cocktail-3 (EspYZU01 + EspYZU03 + EspYZU08 + EspYZU09 + EspYZU10) presented antibacterial efficacy against C. sakazakii in milk for $6 \mathrm{~h}$ at $37^{\circ} \mathrm{C}, 9 \mathrm{~h}$ at $25^{\circ} \mathrm{C}$, and 5 days at $4^{\circ} \mathrm{C}$. These results suggest that this phage cocktail may be used to develop a novel phage biocontrol agent against $C$. sakazakii in dairy and its production environment.

\section{Acknowledgements}

This work was financially supported by the the National Natural Science Foundation of China (Grant numbers: 31371806 and 32001661); the Natural Science 
Foundation of Jiangsu Province, China (Grant number: BK20190890); Jiangsu Agricultural Science and Technology Innovation Fund, China (Grant numbers: CX(15) 1013 and CX(15)1012); and the Science and Technology Innovation Team Fund of Yangzhou University (2016).

\section{References}

Abbasifar, R., Kropinski, A.M., Sabour, P.M., Chambers, J.R., MacKinnon, J., Malig, T. and Griffiths, M.W., 2014. Efficiency of bacteriophage therapy against Cronobacter sakazakii in Galleria mellonella (greater wax moth) larvae. Archives of Virology 159(9): 2253-2261. https://doi.org/10.1007/s00705-014-2055-x

Asakura, H., Morita-Ishihara, T., Yamamoto, S. and Igimi, S., 2007. Genetic characterization of thermal tolerance in Enterobacter sakazakii. Microbiology and Immunology 51(7): 671-677. https://doi.org/10.1111/j.1348-0421.2007.tb03955.x

Bigot, B., Lee, W.-J., McIntyre, L., Wilson, T., Hudson, J., Billington, C. and Heinemann, J. 2011. Control of Listeria monocytogenes growth in a ready-to-eat poultry product using a bacteriophage. Food Microbiology 28(8): 1448-1452. https:// doi.org/10.1016/j.fm.2011.07.001

Brady, C., Cleenwerck, I., Venter, S., Coutinho, T. and De Vos, P., 2013. Taxonomic evaluation of the genus Enterobacter based on multilocus sequence analysis (MLSA): proposal to reclassify E. nimipressuralis and E. amnigenus into Lelliottia gen. nov. as Lelliottia nimipressuralis comb. nov. and Lelliottia amnigena comb. nov., respectively, E. gergoviae and E. pyrinus into Pluralibacter gen. nov. as Pluralibacter gergoviae comb. nov. and Pluralibacter pyrinus comb. nov., respectively, E. cowanii, E. radicincitans, E. oryzae and E. arachidis into Kosakonia gen. nov. as Kosakonia cowanii comb. nov., Kosakonia radicincitans comb. nov., Kosakonia oryzae comb. nov. and Kosakonia arachidis comb. nov., respectively, and E. turicensis, E. helveticus and E. pulveris into Cronobacter as Cronobacter zurichensis nom. nov., Cronobacter helveticus comb. nov. and Cronobacter pulveris comb. nov., respectively, and emended description of the genera Enterobacter and Cronobacter. Systematic and Applied Microbiology 36(5): 309-319. https://doi. org/10.1016/j.syapm.2013.03.005

Brüssow, H., Canchaya, C. and Hardt, W.D., 2004. Phages and the evolution of bacterial pathogens: from genomic rearrangements to lysogenic conversion. Microbiology and Molecular Biology Reviews 68(3): 560-602. https://doi.org/10.1128/MMBR.68.3.560-602.2004

Carlton, R., Noordman, W., Biswas, B., De Meester, E. and Loessner, M.J., 2005. Bacteriophage P100 for control of Listeria monocytogenes in foods: genome sequence, bioinformatic analyses, oral toxicity study, and application. Regulatory Toxicology and Pharmacology 43(3): 301-312. https://doi.org/10.1016/j.yrtph.2005.08.005

Caubilla-Barron J., Hurrell E., Townsend S., Cheetham P., LocCarrillo C., Fayet O., Prere M.F. and Forsythe S.J., 2007. Genotypic and phenotypic analysis of Enterobacter sakazakii strains from an outbreak resulting in fatalities in a neonatal intensive care unit in France. Journal of Clinical Microbiology 45, 3979-3985. https://doi.org/10.1128/JCM.01075-07
Drudy, D., Mullane, N.R., Quinn, T., Wall, P.G. and Fanning, S., 2006. Enterobacter sakazakii: an emerging pathogen in powdered infant formula. Clinical Infectious Diseases 42(7): 9961002. https://doi.org/10.1086/501019

Ellis, D., Whitman, P. and Marshall, R., 1973. Effects of homologous bacteriophage on growth of Pseudomonas fragi WY in milk. Applied Microbiology 25(1): 24-25. https://doi.org/10.1128/ am.25.1.24-25.1973

Endersen, L., Buttimer, C., Nevin, E., Coffey, A., Neve, H., Oliveira, H., Lavigne, R., O'Mahony and J., 2017. Investigating the biocontrol and anti-biofilm potential of a three-phage cocktail against Cronobacter sakazakii in different brands of infant formula. International Journal of Food Microbiology 253, 1-11. https://doi.org/10.1016/j.ijfoodmicro.2017.04.009

Endersen, L., Coffey, A., Neve, H., McAuliffe, O., Ross, R.P. and O'Mahony, J.M., 2013. Isolation and characterisation of six novel mycobacteriophages and investigation of their antimicrobial potential in milk. International Dairy Journal 28(1): 8-14. https://doi.org/10.1016/j.idairyj.2012.07.010

Endersen, L., O’Mahony, J., Hill, C., Ross, R.P., McAuliffe, O. and Coffey, A., 2014. Phage therapy in the food industry. Annual Review of Food Science and Technology 5, 327-349. https://doi. org/10.1146/annurev-food-030713-092415

Farmer, J.J., Asbury, M.A., Hickman, F.W. and Brenner, D.J., 1980. Enterobacter sakazakii: a new species of "Enterobacteriaceae" isolated from clinical specimens. International Journal of Systematic Bacteriology 30(3): 569-584. https://doi. org/10.1099/00207713-30-3-569

Faruque, S.M. and Mekalanos, J.J., 2012. Phage-bacterial interactions in the evolution of toxigenic Vibrio cholerae. Virulence 3(7): 556-565. https://doi.org/10.4161/viru.22351

Food and Agriculture Organization of the United Nations/World Health Organization (FAO/WHO), 2008. Enterobacter sakazakii (Cronobacter spp.) in powdered follow-up formulae: meeting report. Microbiological Risk Assessment Series No. 15. Rome. 84pp. Available at: http://www.fao.org/ag/agn/agns/jemra/Sakazaki_FUF_ report.pdf

Forsythe, S., 2005. Enterobacter sakazakii and other bacteria in powdered infant milk formula. Maternal \& Child Nutrition 1(1): 44. https://doi.org/10.1111/j.174.0-8709.2004.00008.x

Friedemann, M., 2009. Epidemiology of invasive neonatal Cronobacter (Enterobacter sakazakii) infections. European Journal of Clinical Microbiology \& Infectious Diseases 28(11): 1297-1304. https://doi.org/10.1007/s10096-009-0779-4

Goodridge, L.D. and Bisha, B., 2014. Phage-based biocontrol strategies to reduce food borne pathogens in foods. Bacteriophage 1(3): 130-137. https://doi.org/10.4161/bact.1.3.17629

Hawkins, R., Lissner, C. and Sanford, J.P., 1991. Enterobacter sakazakii bacteremia in an adult. Southern Medical Journal 84(6): 793-795. https://doi.org/10.1097/00007611-19910600000033

Healy, B., Cooney, S., O’Brien, S., Iversen, C., Whyte, P., Nally, J., Callanan, J.J. and Fanning, S., 2010. Cronobacter (Enterobacter sakazakii): an opportunistic food-borne pathogen. Foodborne Pathogens and Disease 7(4): 339-350. https://doi.org/10.1089/ fpd.2009.0379 
Himelright I., Harris E., Lorch V., Anderson M., Jones T., Craig A., Kuehnert M., Forster T., Arduino M., Jensen B. and Jernigan D., 2002. Enterobacter sakazakii infections associated with the use of powdered infant formula-Tennessee, 2001. Journal of the American Medical Directors Association 287: 2204-2205.

Holý, O. and Forsythe, S., 2014. Cronobacter spp. as emerging causes of healthcare-associated infection. Journal of Hospital Infection 86(3): 169-177. https://doi.org/10.1016/j.jhin.2013.09.011

Iversen, C., Lehner, A., Mullane, N., Bidlas, E., Cleenwerck, I., Marugg, J., Fanning, S., Stephan, R. and Joosten, H., 2007. The taxonomy of Enterobacter sakazakii: proposal of a new genus Cronobacter gen. nov. and descriptions of Cronobacter sakazakii comb. nov. Cronobacter sakazakii subsp. sakazakii, comb. nov., Cronobacter sakazakii subsp. malonaticus subsp. nov., Cronobacter turicensis sp. nov., Cronobacter muytjensii sp. nov., Cronobacter dublinensis sp. nov. and Cronobacter genomospecies 1. BMC Evolutionary Biology 7, 64. https://doi. org/10.1186/1471-2148-7-64

Jepson, C.D. and March, J.B., 2004. Bacteriophage lambda is a highly stable DNA vaccine delivery vehicle. Vaccine 22(19): 2413-2419. https://doi.org/10.1016/j.vaccine.2003.11.065

Joseph, S., Cetinkaya, E., Drahovska, H., Levican, A., Figueras, M.J. and Forsythe, S.J., 2012. Cronobacter condimenti sp. nov., isolated from spiced meat, and Cronobacter universalis sp. nov., a species designation for Cronobacter sp. genomospecies 1 , recovered from a leg infection, water and food ingredients. International Journal of Systematic and Evolutionary Microbiology 62(Pt 6): 1277-1283. https://doi.org/10.1099/ ijs.0.032292-0

Kajsík, M., Oslanecová, L., Szemes, T., Hýblová, M., Bilková, A., Drahovská, H. and Turňa, J., 2014. Characterization and genome sequence of Dev2, a new T7-like bacteriophage infecting Cronobacter turicensis. Archives of Virology 159(11): 30133019. https://doi.org/10.1007/s00705-014-2173-5

Kandhai, M.C., Reij, M.W., Gorris, L.G., Guillaume-Gentil, O. and van Schothorst, M., 2004. Occurrence of Enterobacter sakazakii in food production environments and households. The Lancet 363(9402): 39-40. https://doi.org/10.1016/ S0140-6736(03)15169-0

Kim, K.P., Klumpp, J. and Loessner, M.J., 2007. Enterobacter sakazakii bacteriophages can prevent bacterial growth in reconstituted infant formula. International Journal of Food Microbiology 115(2): 195-203. https://doi.org/10.1016/j. ijfoodmicro.2006.10.029

Lai, K.K., 2001. Enterobacter sakazakii infections among neonates, infants, children, and adults: case reports and a review of the literature. Medicine 80(2): 113-122. https://doi. org/10.1097/00005792-200103000-00004

Lee, J.H., Bai, J., Shin, H., Kim, Y., Park, B., Heu, S., Ryu, S. and Schottel, J.L., 2016a. A novel bacteriophage targeting Cronobacter sakazakii is a potential biocontrol agent in foods. Applied and Environmental Microbiology 82(1): 192-201. https://doi.org/10.1128/AEM.01827-15

Lee, H.J., Kim, W.I., Kwon, Y.C., Cha, K.E., Kim, M. and Myung, H., 2016b. A newly isolated bacteriophage, PBES 02, infecting
Cronobacter sakazakii. Journal of Microbiology and Biotechnology 26(9): 1629-1635. https://doi.org/10.4014/jmb.1605.05020

Lepuschitz, S., Ruppitsch, W., Pekard-Amenitsch, S., Forsythe, S.J., Cormican, M., Mach, R.L., Pierard, D. and Allerberger, F., 2019. Multicenter study of Cronobacter sakazakii infections in humans, Europe, 2017. Emerging Infectious Diseases 25(3): 515-522. https://doi.org/10.3201/eid2503.181652

Magnani, C.F., Mezzanotte C., Cappuzzello C., Bardini M., Tettamanti S., Fazio G., Cooper L.J.N., Dastoli G., Cazzaniga G., Biondi A. and Biagi E., 2018. Preclinical efficacy and safety of CD19CAR cytokine-induced killer (CIK) cells transfected with Sleeping Beauty transposon for the treatment of acute lymphoblastic leukemia. Human Gene Therapy 29 (5): 602-613. https:// doi.org/10.1089/hum.2017.207

Nazarowec-White, M. and Farber, J.M., 1997. Enterobacter sakazakii: a review. International Journal of Food Microbiology 34.(2): 103-113. https://doi.org/10.1016/S0168-1605(96)01172-5

See, K., Than, H. and Tang, T., 2007. Enterobacter sakazakii bacteraemia with multiple splenic abscesses in a 75-year-old woman: a case report. Age and Ageing 36(5): 595-596. https://doi. org/10.1093/ageing/afm092

Stoll B.J., Hansen N., Fanaroff A.A. and Lemons J.A., 2004. Enterobacter sakazakii is a rare cause of neonatal septicemia or meningitis in VLBW infants. JAMA Pediatrics 144: 821-823. https://doi.org/10.1016/S0022-3476(04)00175-1 https://doi. org/10.1016/j.jpeds.2004.02.045

Tey, B.T., Ooi, S.T., Yong, K.C., Ng, M.Y.T., Ling, T.C. and Tan, W.S., 2009. Production of fusion $\mathrm{m} 13$ phage bearing the di-sulphide constrained peptide sequence (C-WSFFSNI-C) that interacts with hepatitis B core antigen. African Journal of Biotechnology 8(2): 268-273. Corpus ID: 59467076

Tóthová, L., Celec, P., Bábíčková, J., Gajdošová, J., Al-Alami, H., Kamodyova, N., Drahovska, H., Liptakova, A., Turňa, J. and Hodosy, J., 2011. Phage therapy of Cronobacter-induced urinary tract infection in mice. Medical Science Monitor: International Medical Journal of Experimental and Clinical Research 17(7): BR173. https://doi.org/10.12659/MSM.881844

Yan, Q., Condell, O., Power, K., Butler, F., Tall, B. and Fanning, S., 2012. Cronobacter species (formerly known as Enterobacter sakazakii) in powdered infant formula: a review of our current understanding of the biology of this bacterium. Journal of Applied Microbiology 113(1): 1-15. https://doi. org/10.1111/j.1365-2672.2012.05281.x

Zhang, Y., Zhang Z., Ding Y., Fang Y., Wang P., Chu W., Jin Z., Yang X., Wang J., Lou J., and Qian Q. 2021. Phase I clinical trial of EGFR-specific CAR-T cells generated by the piggyBac transposon system in advanced relapsed/refractory non-small cell lung cancer patients. Journal of Cancer Research and Clinical Oncology. https://doi.org/10.1007/s00432-021-03613-7

Zuber, S., Boissin-Delaporte, C., Michot, L., Iversen, C., Diep, B., Brüssow, H. and Breeuwer, P. 2008. Decreasing Enterobacter sakazakii (Cronobacter spp.) food contamination level with bacteriophages: prospects and problems. Microbial biotechnology, 1(6): 532-543. https://doi.org/10.1111/j.1751-7915.2008.00058.x 


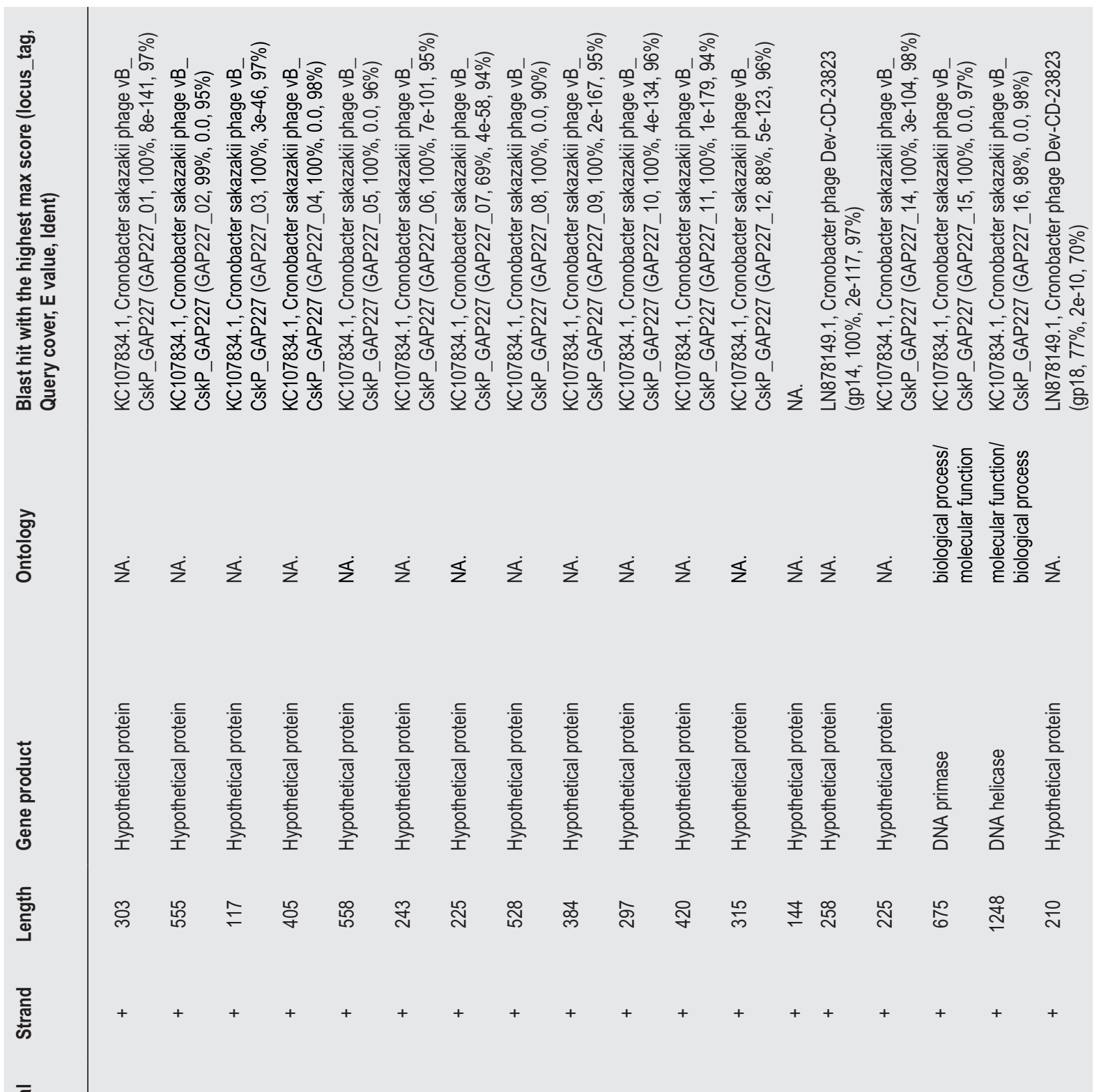

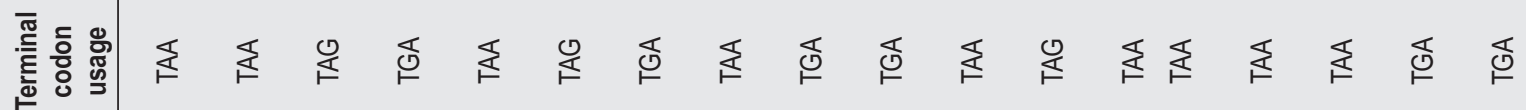

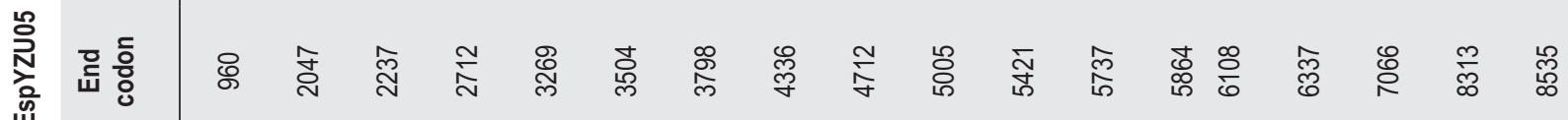

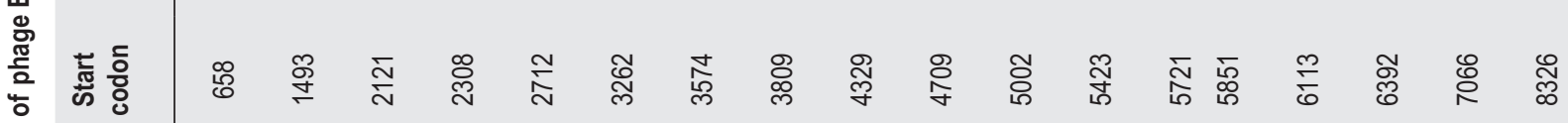
竞

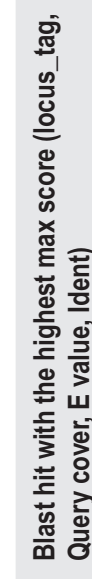

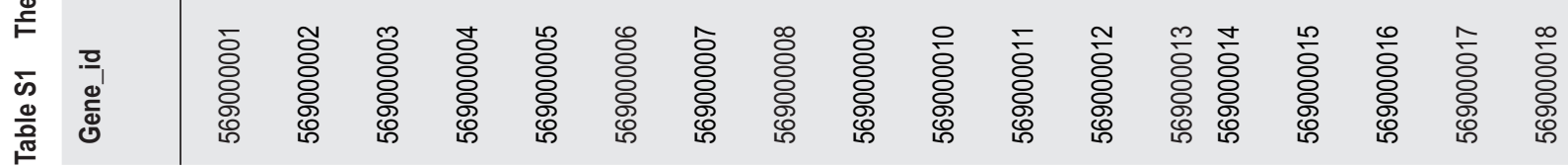




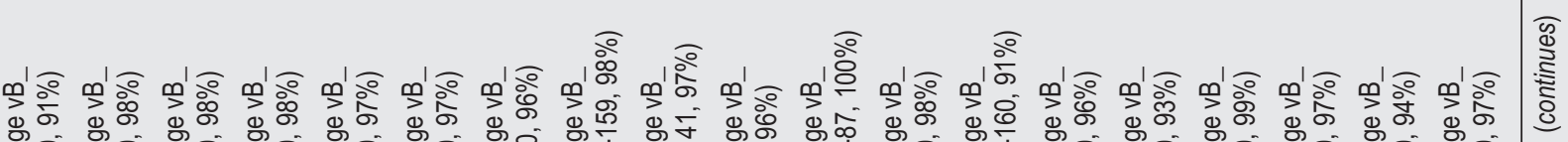

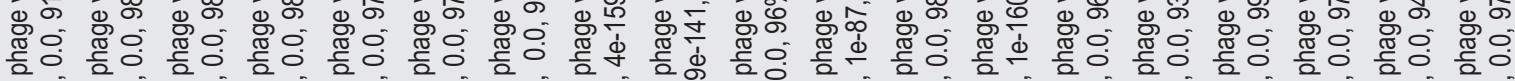

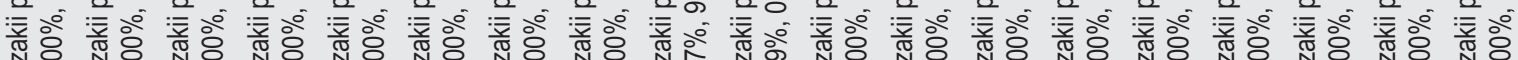

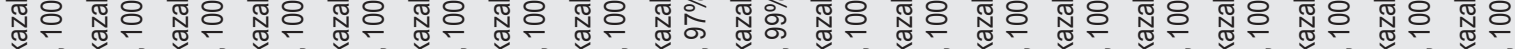

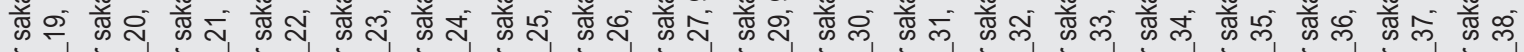

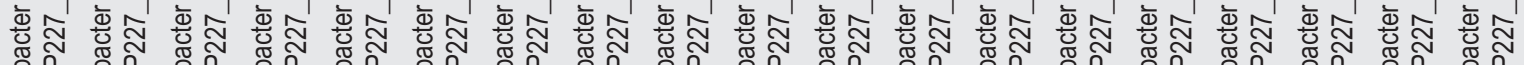

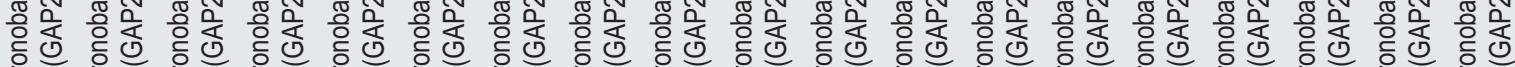

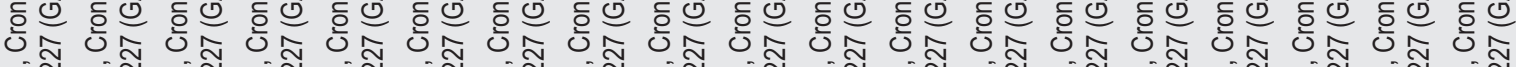

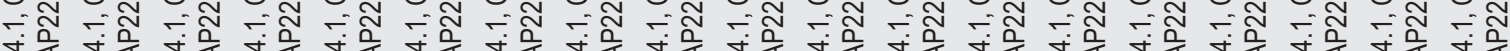

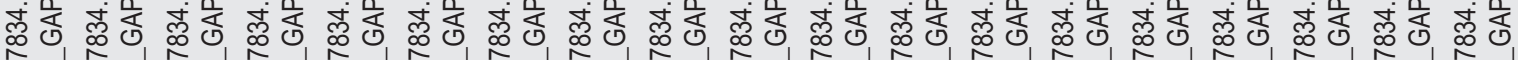

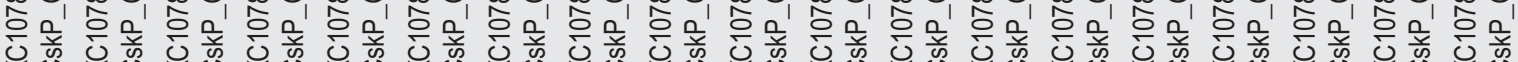

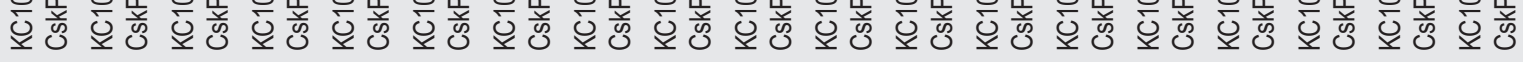

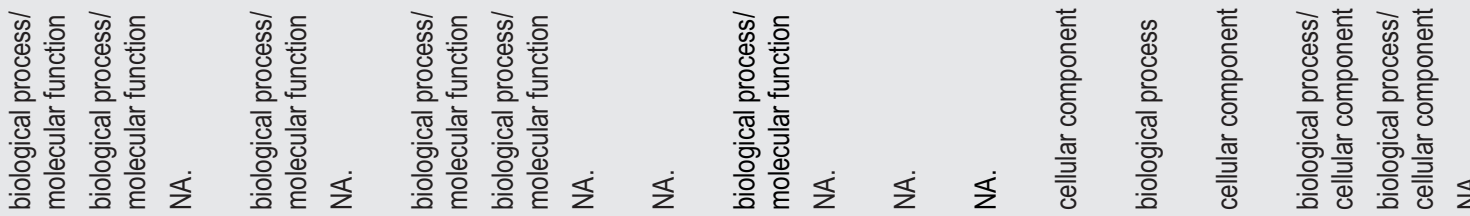

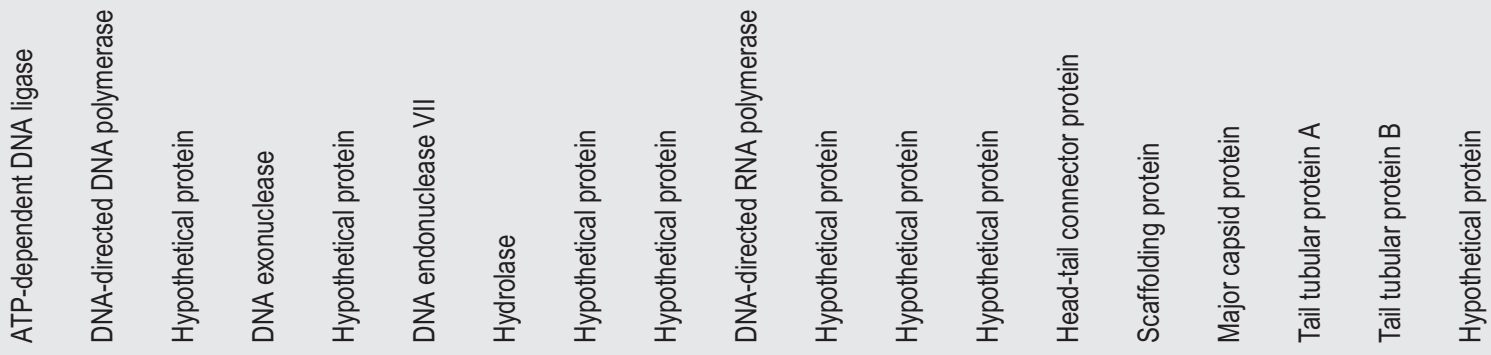

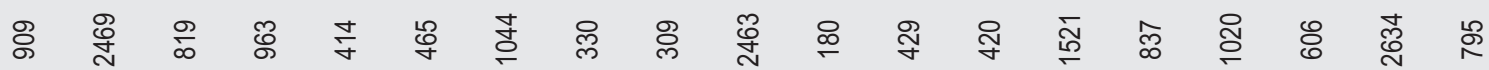

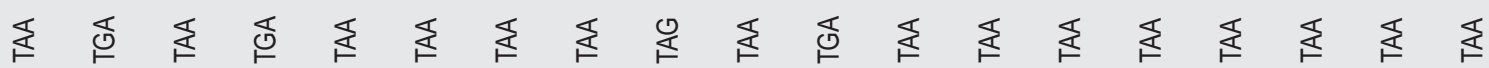

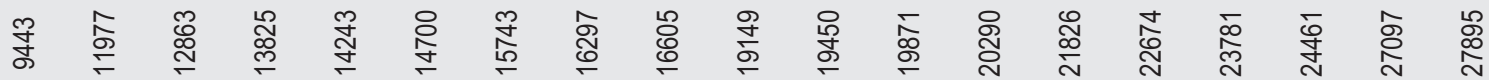

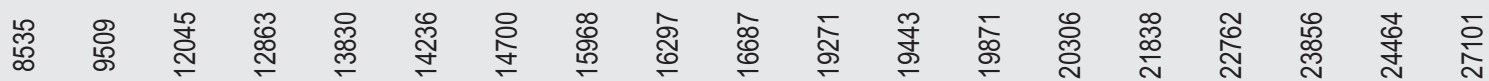

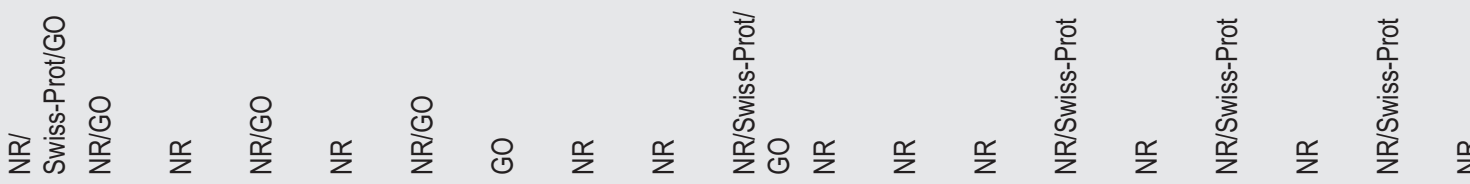

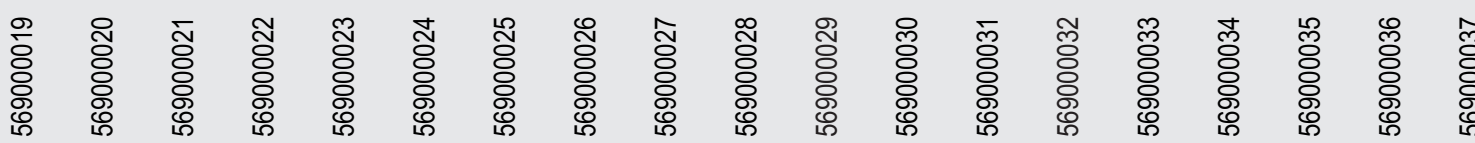




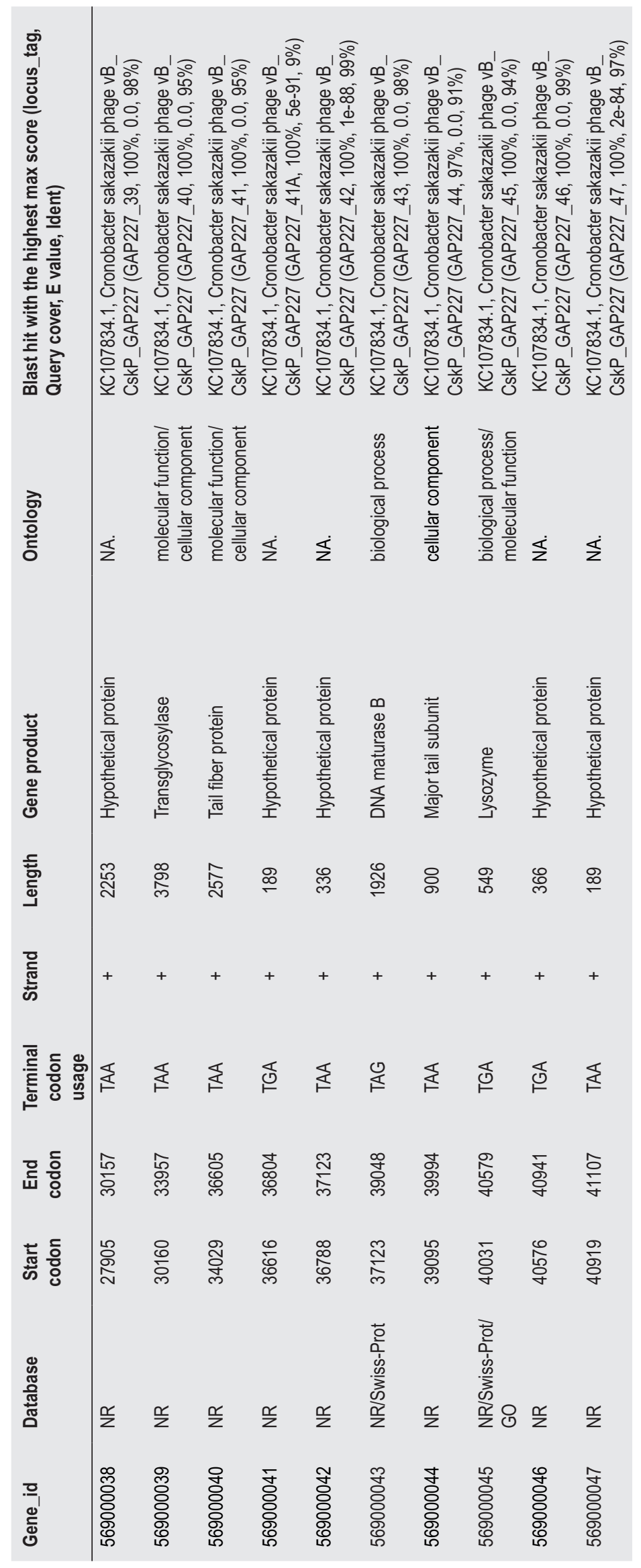



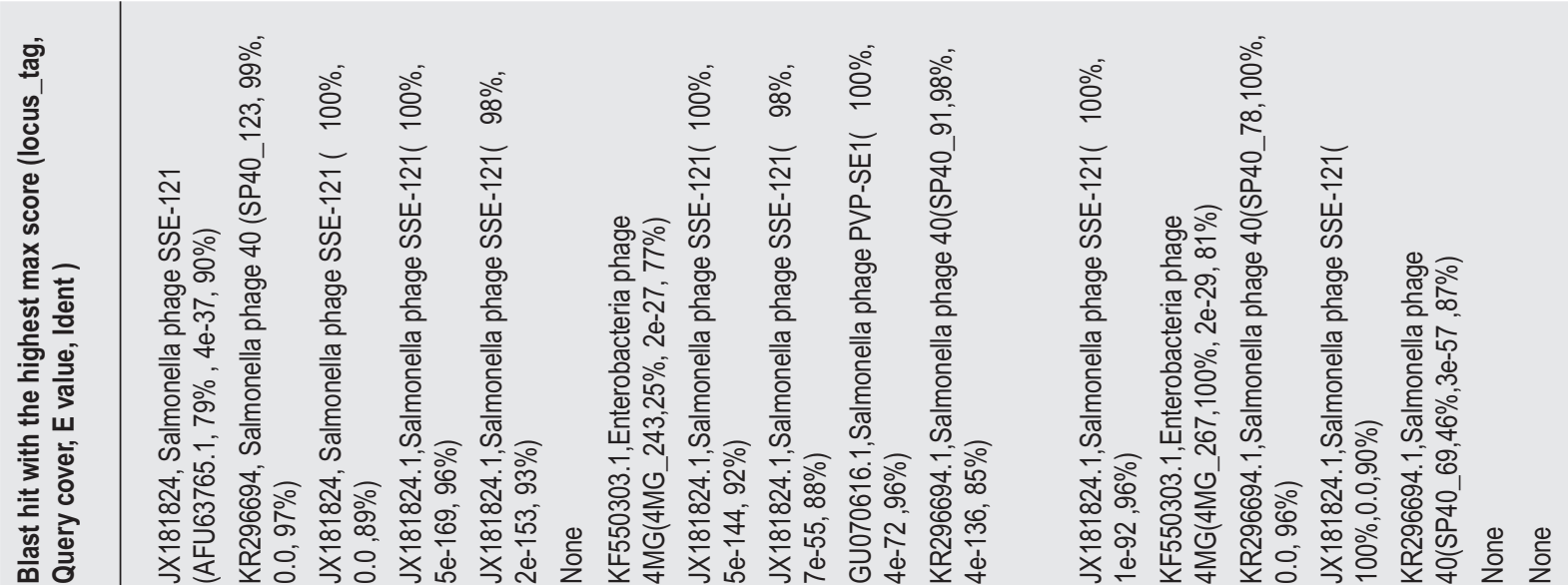

흥

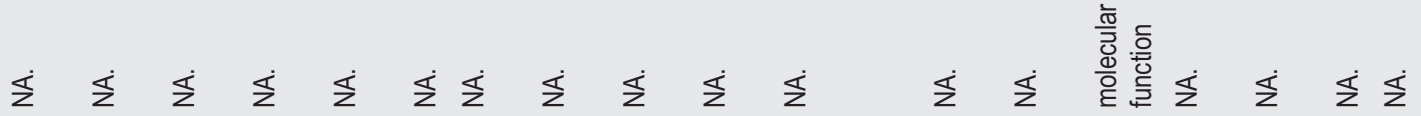

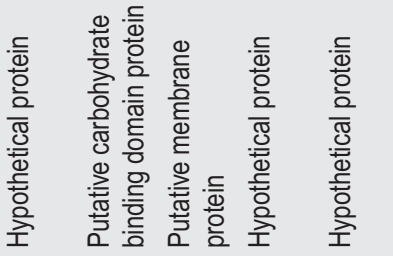
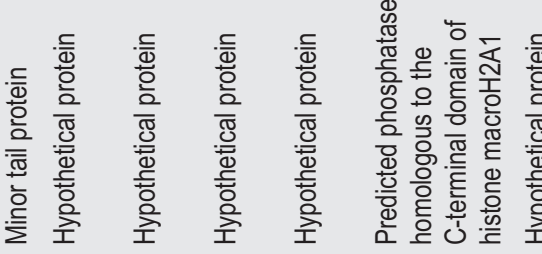

홇

ণ

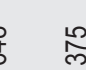

৪

岕 ণิ

$\stackrel{6}{\mathscr{Q}}$

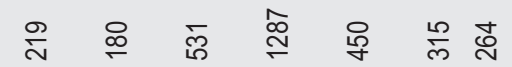

홀

承

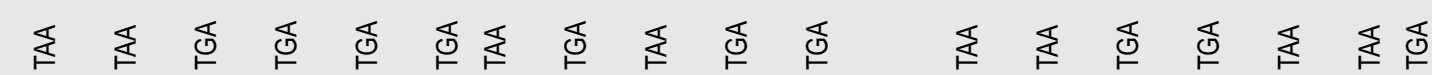

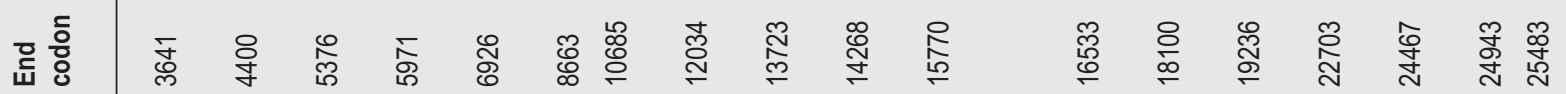

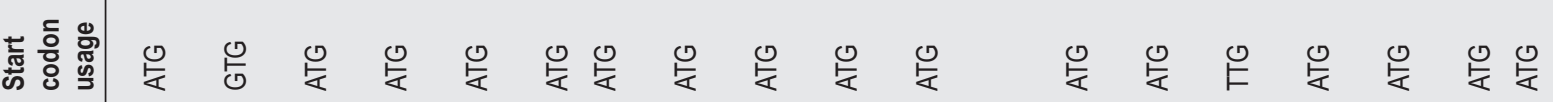

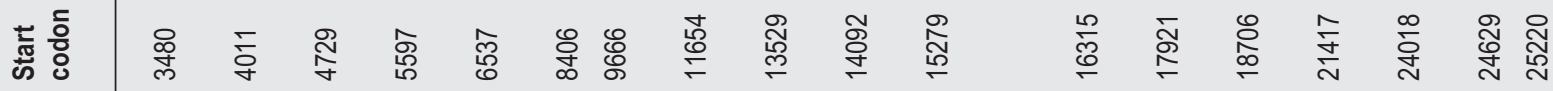
$\stackrel{\Xi}{5}$

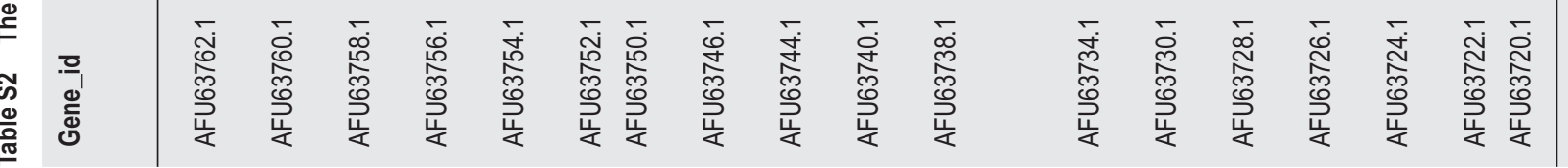




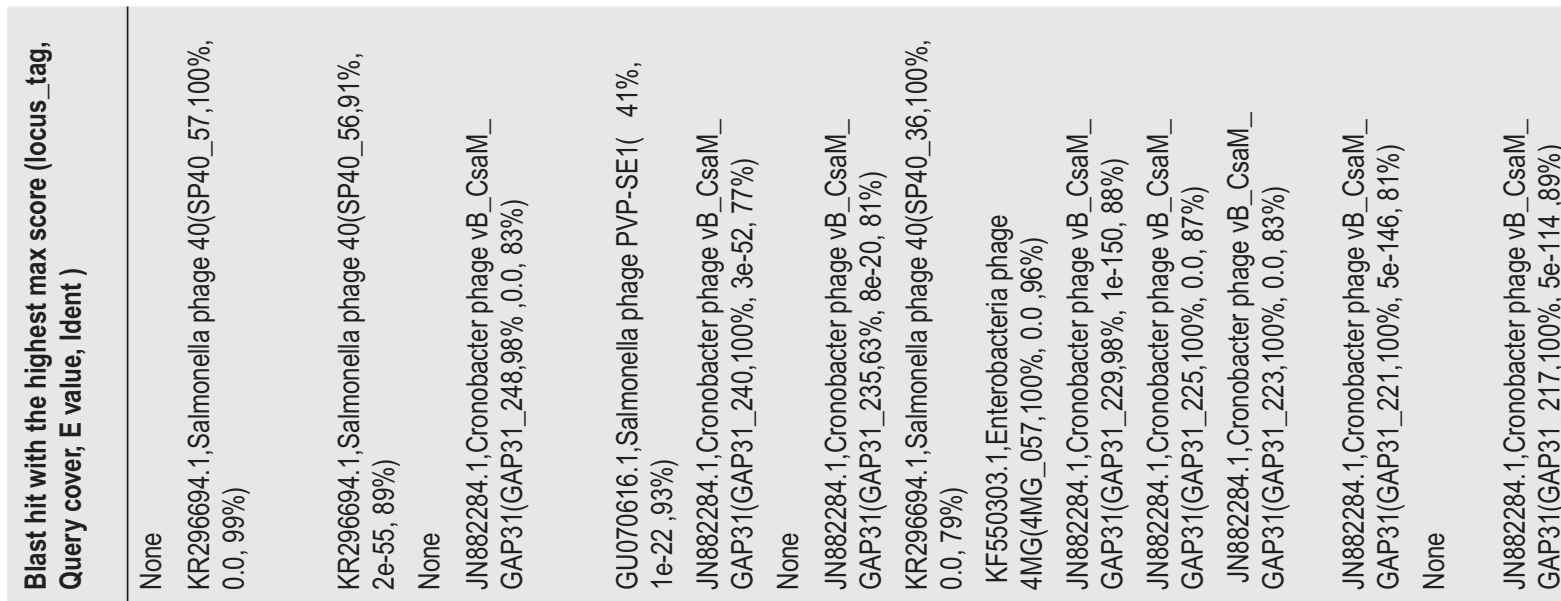

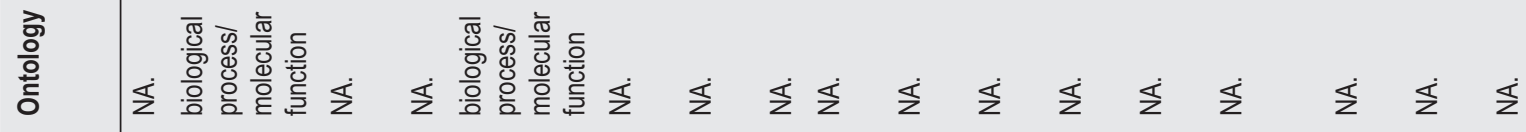

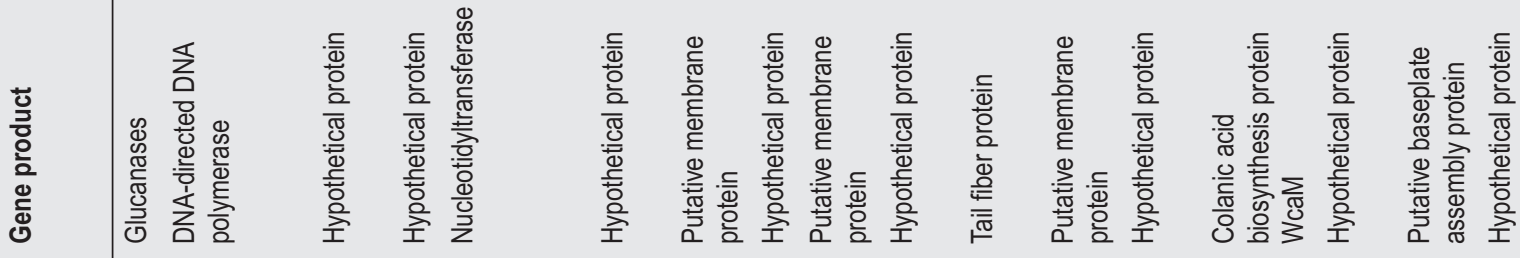

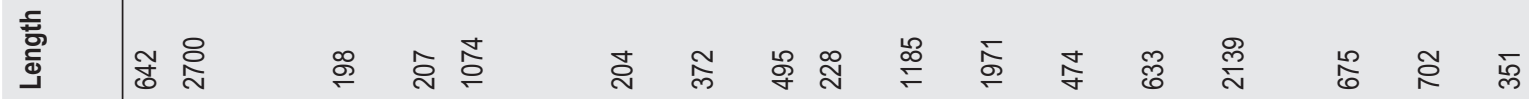
总

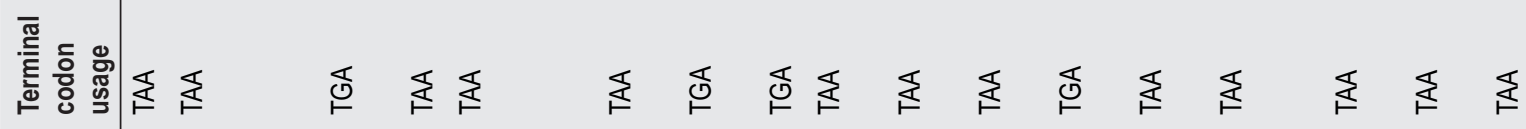

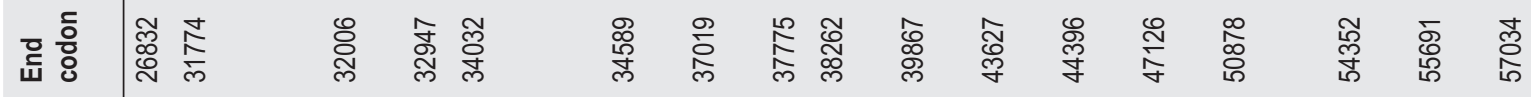

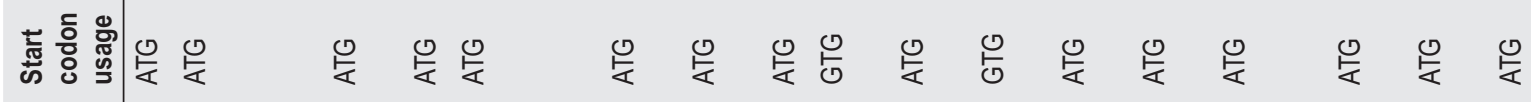

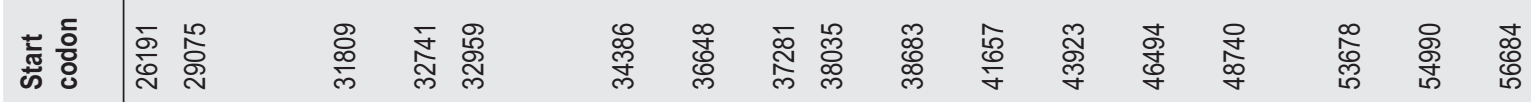

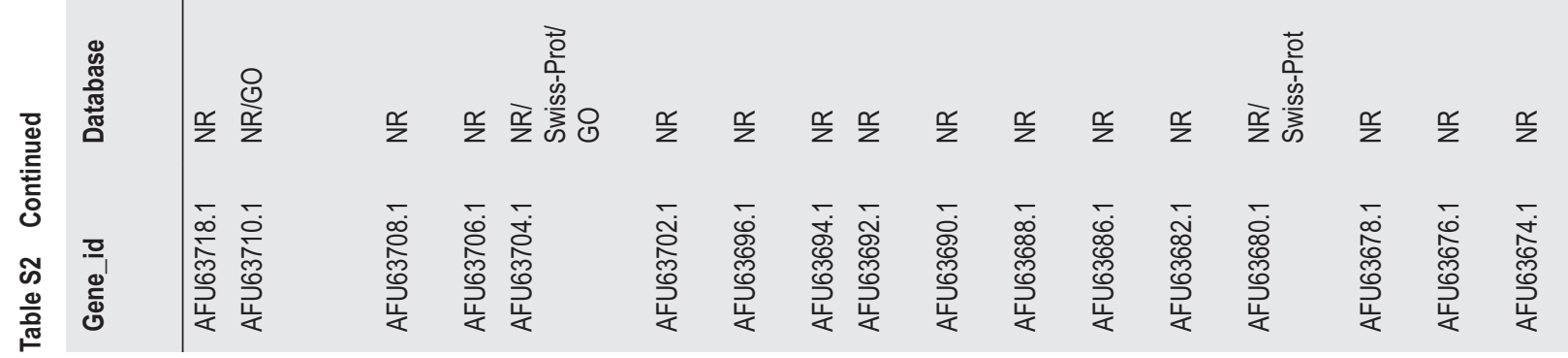



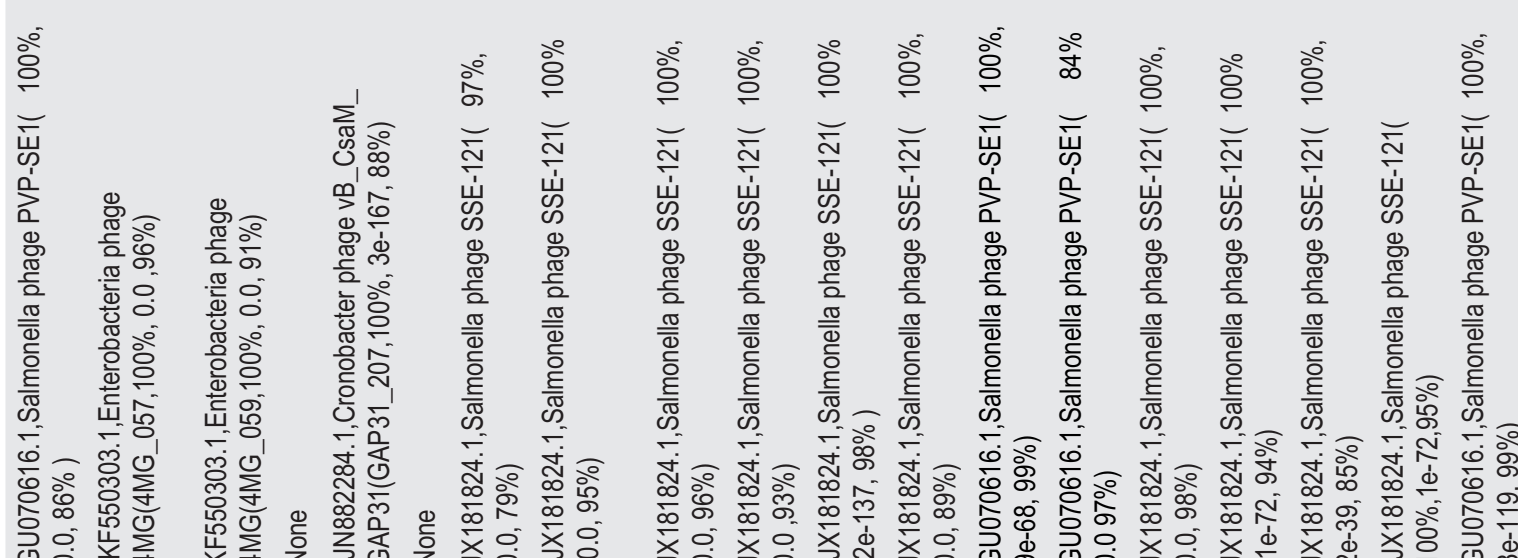

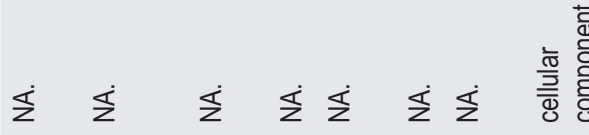
安

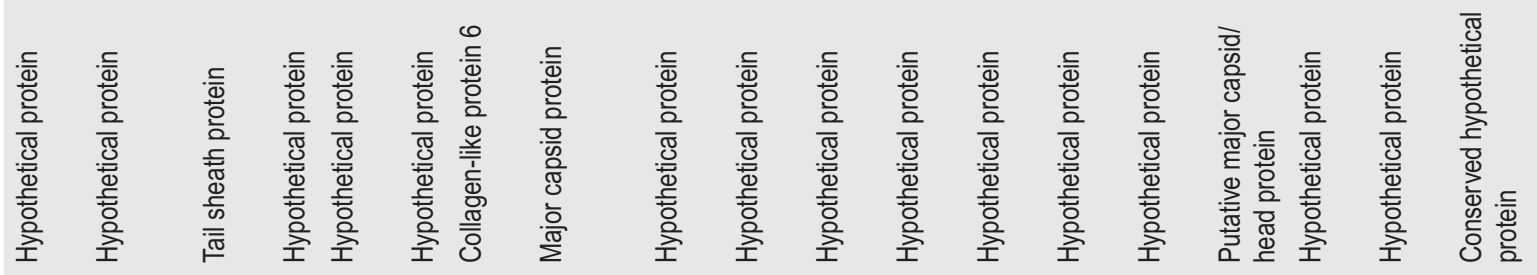

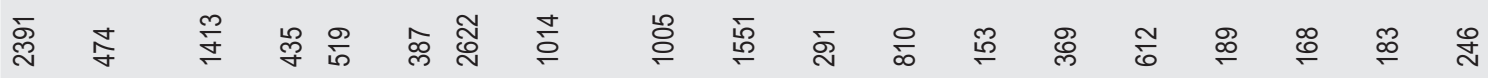

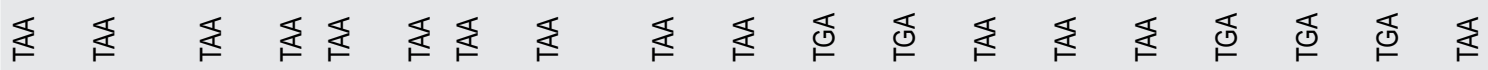

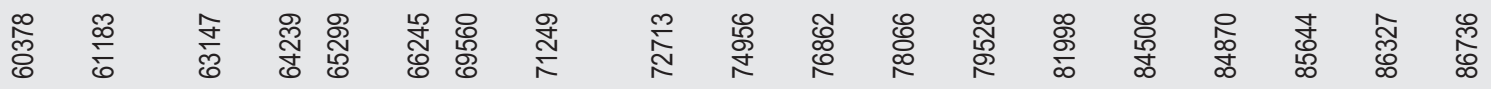

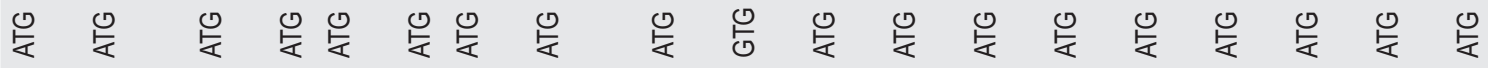

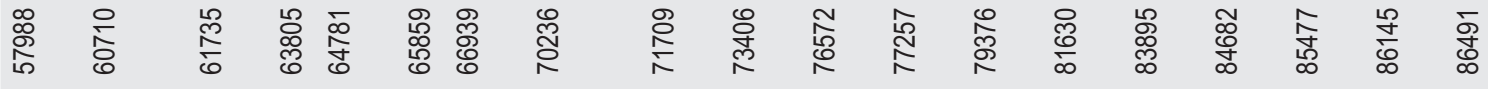

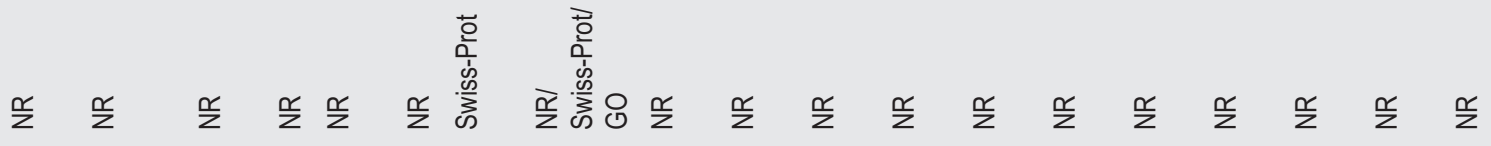

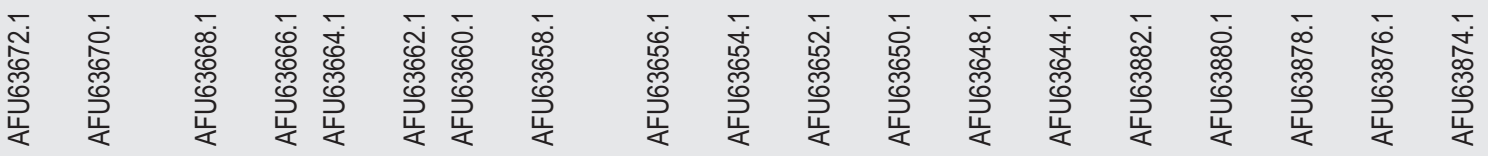




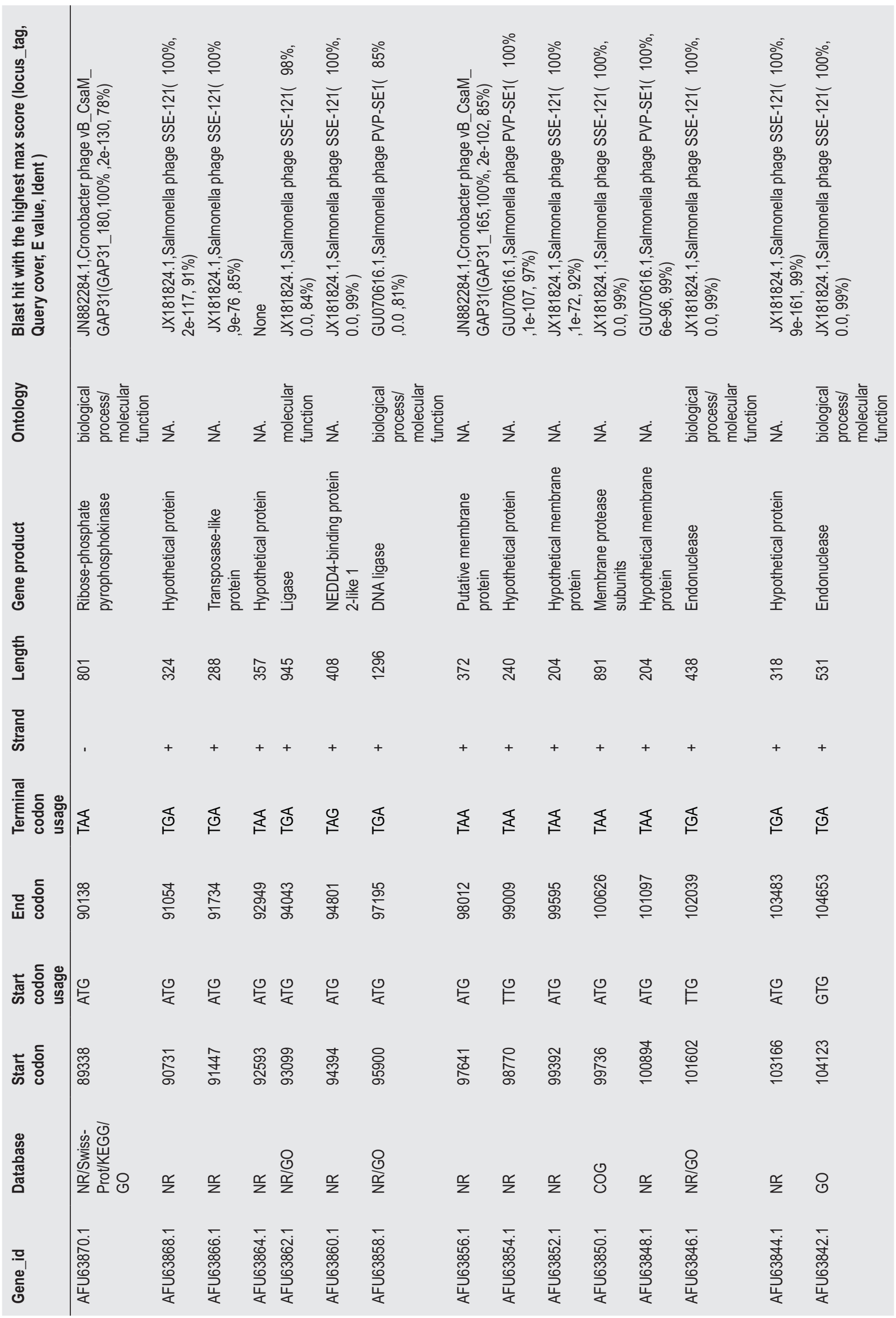




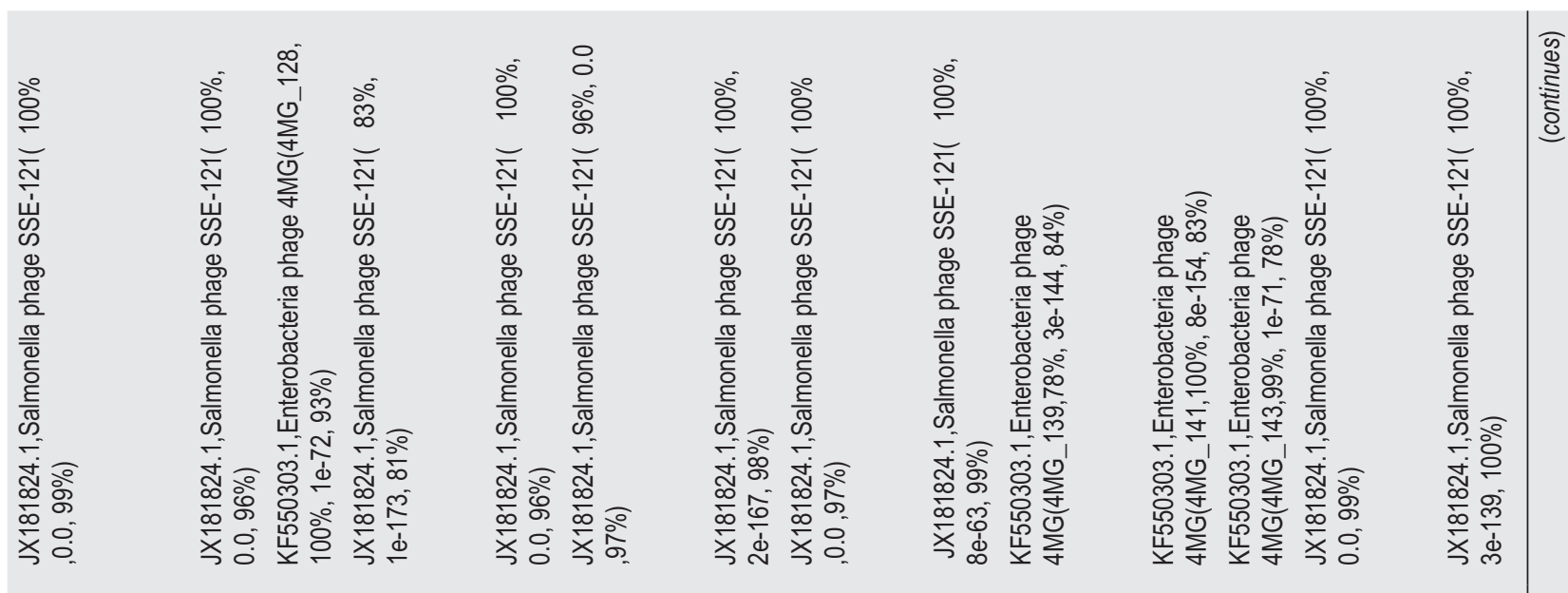

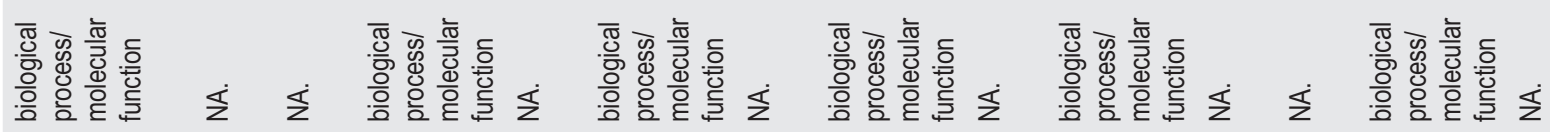

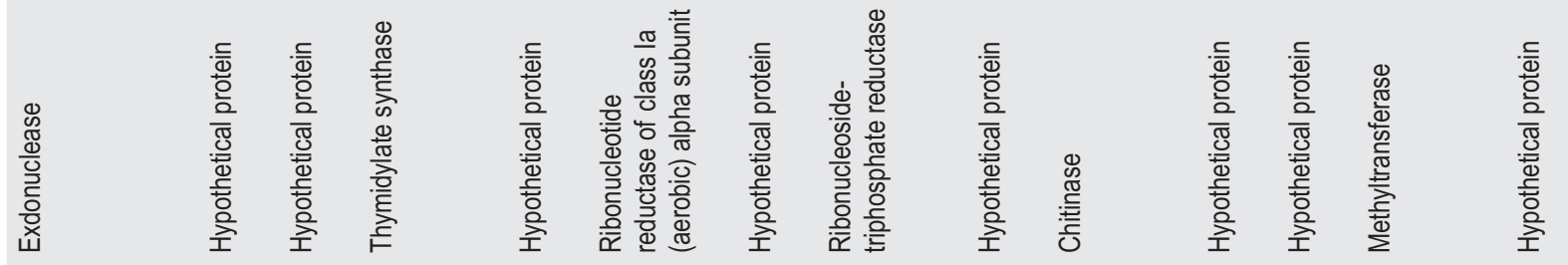

今 \& \& \& \&

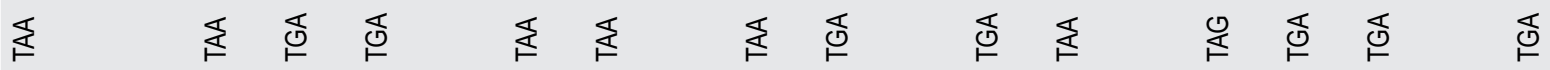

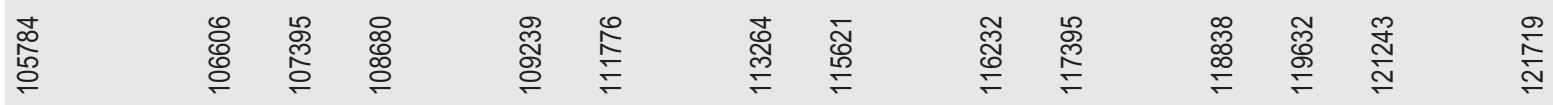

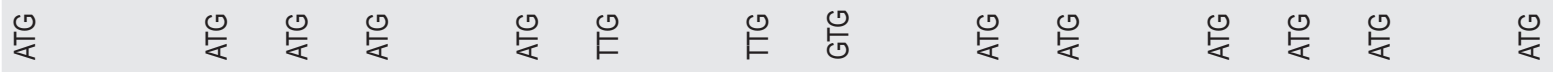

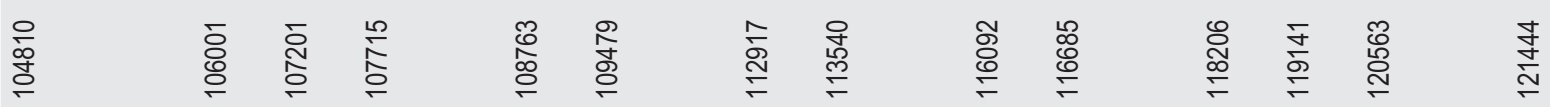

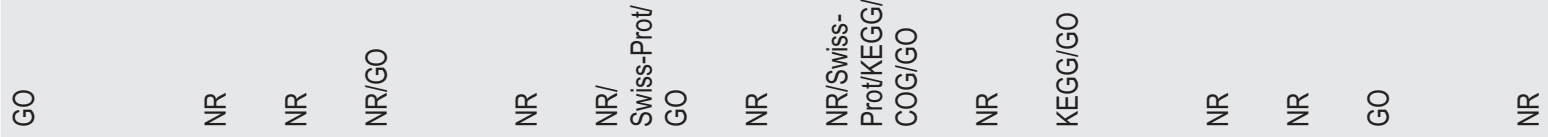

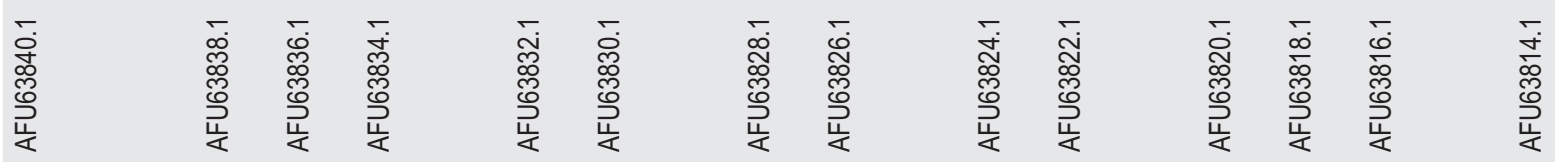




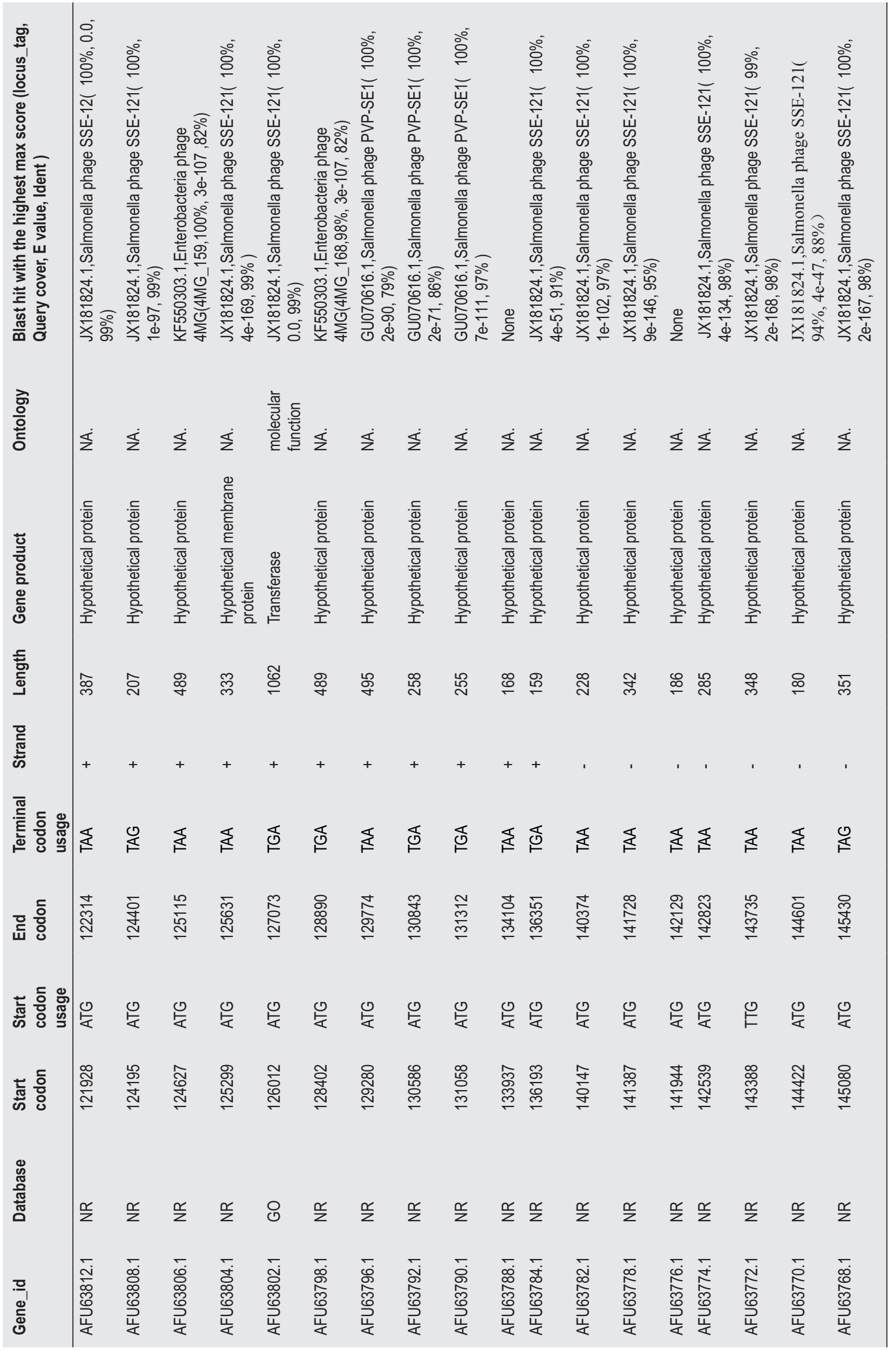

